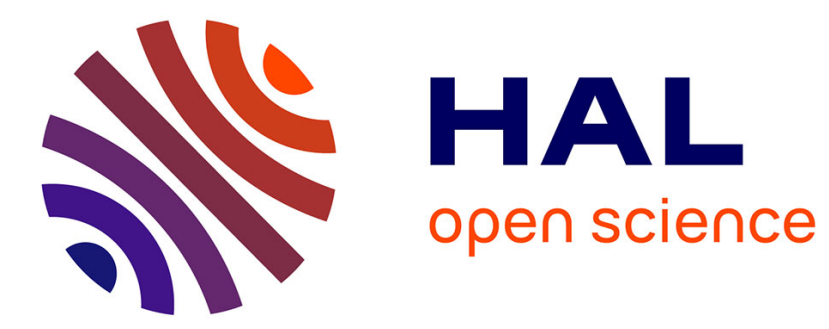

\title{
Inscriptions nouvelles de la Drôme et de l'Ardèche
} André Blanc, Henri Desaye

\section{To cite this version:}

André Blanc, Henri Desaye. Inscriptions nouvelles de la Drôme et de l'Ardèche. Gallia - Fouilles et monuments archéologiques en France métropolitaine, 1975, 33 (2), pp.229-256. 10.3406/galia.1975.1524. hal-01934193

\section{HAL Id: hal-01934193 \\ https://hal.science/hal-01934193}

Submitted on 11 Mar 2020

HAL is a multi-disciplinary open access archive for the deposit and dissemination of scientific research documents, whether they are published or not. The documents may come from teaching and research institutions in France or abroad, or from public or private research centers.
L'archive ouverte pluridisciplinaire HAL, est destinée au dépôt et à la diffusion de documents scientifiques de niveau recherche, publiés ou non, émanant des établissements d'enseignement et de recherche français ou étrangers, des laboratoires publics ou privés.

\section{(이)(\$)}

Distributed under a Creative Commons Attribution - NonCommercial - NoDerivatives| 4.0 


\title{
INSCRIPTIONS NOUVELLES DE LA DRÔME ET DE L'ARDĖCHE
}

\author{
par André BLANC et Henri DESAYE
}

\section{Inscriptions DE LA CitÉ de Valence}

Au cours de l'été 1973 une découverte archéologique a été faite à Valence, sur le chantier de l'hôtel des Postes, situé sur le boulevard Édouard-Herriot, entre les immeubles de la Sécurité Sociale et la nouvelle préfecture de la Drôme.

Sur ces emplacements avait été édifié, au milieu du $\mathrm{xIx}^{\mathbf{e}}$ s., le quartier Chareton, la grande caserne d'artillerie détruite en 1944. Cette construction avait remplacé la Citadelle établie dans les dernières années du $\mathrm{XvI}^{\mathrm{e}} \mathrm{s} .^{1}$ Ce vaste terrain, occupé par les militaires depuis près de quatre siècles se trouvait à cheval sur la ligne du pomerium de la ville romaine, parfaitement reconnue, grâce à sa régularité géométrique ${ }^{2}$ épousant la topographie des lieux. Elle suivait dans ce secteur, au nord et à l'ouest, le bord de la terrasse de $25 \mathrm{~m}$ dominant le Rhône. Le chantier

1 Pour construire la Citadelle, en 1582, on avait démoli 213 maisons et cxproprié de nombreux jardins. C'est dans l'un des bâtiments, appelé la maison du gouverneur, que le pape Pie VI, prisonnier du Directoire, mourut le 29 aoùt 1799.

2 Les limites de la ville romaine, de fondation coloniale, ont été reconnues sur le terrain. Elles formaient un rectangle régulier de $700 \mathrm{~m}$ sur $350 \mathrm{~m}$ environ qui s'intégrait fort bien à la topographie pour utiiiser les défenses naturelles sur sés trois cỏtés. De plus ces axes principaux étaient directement liés à la centuriation des campagnes voisines, dont les traces sont encore visibles sur une grande étendue. de la nouvelle poste occupait l'emplacement qui, sur le plan du Valence gallo-romain, correspondait à la partie ouest de la porte municipale nord, livrant passage à la voie antique (fig. 1). Cette dernière traversait l'une des nécropoles de la ville établie en contrebas et se rapprochait du Rhône pour reprendre, à proximité de l'actuelle église Saint-Pierredu-Bourg, construite à l'emplacement de la basilique suburbaine déjà dédiée à SaintPierre $^{3}$, une direction parallèle au fleuve. Dans le chantier, les terrassements descendirent entre 4 et $5 \mathrm{~m}$ sous le niveau du sol actuel ; il fut possible de retrouver les restes de la muraille médiévale qui ne reposait dans ce secteur, contrairement à ce qui avait été rencontré au sud, sur aucun vestige plus ancien.

Le quartier, connu sous le nom d'Aïon au Moyen $\mathrm{Age}^{4}$, avait été fort bouleversé par les

3 Le site de Saint-Pierre-du-Bourg, proche du port fluvial gallo-romain, a livré des fragments de sarcophages et plusieurs inscriptions chrétiennes. A. Bt.ANc, Valence des Origines aux Carolingiens, Valence, 196.4, p. 132.

4 Via publica Turris d'Aionis, $\mathrm{xII}^{\mathrm{e}} \mathrm{s}$. (Cartularium ecclesiae Sancti Pelri de Burgo Valenliae, U. Chevalier, Valence, 1881 , p. 23 et 25 ). Ce nom se transformera à la fin du Moyen Age en Tourdéon (cadastre de Valence de 1547). On a quelquefois vu un rapport entre le mot Aion et le culte de Mithra. A Valence, Mithra avait des sectateurs, deux inscriptions, dont l'une trouvée dans ce quartier, E. EspéraNDIEc, Inscriptions latines dela $\mathrm{G}$ aule Narbonnaise, Paris, 1929 (en abrégé : ILGN, 258 et A. Blanc, Gallia, XVIII, 1960, p. 201, le confirment. 


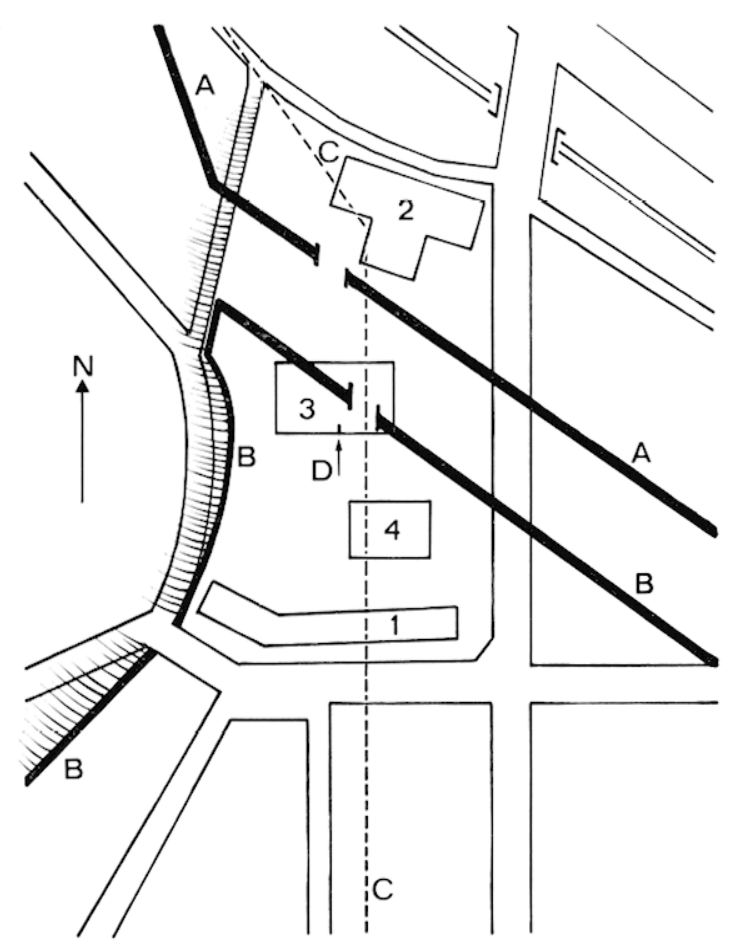

1 Plan de l'ancien quartier Aion : 1 préfecture de la Dròme ; 2 services de la sécurité sociale ; 3 nouvel hôtel des postes; 4 chantier de la trésorerie générale; $\mathrm{A}$ enccinte médiévale extérieure; $\mathrm{B}$ enceinte intérieure correspondant à celle du Bas-Empire ; $\mathrm{C}$ axe du cardo se continuant au nord par la voie d'Agrippa en direction de Lyon; D lieu de la découverte.

travaux militaires du $\mathrm{Xv}^{\mathrm{e}} \mathrm{e}^{\mathrm{s}}$., $œ u v r e$ qui fut achevée par la construction de la caserne au $\mathrm{XIX}^{\mathrm{e}} \mathrm{s}$.

C'est au cours des terrassements qu'un engin devait écorner, en bordure sud du chantier, une lentille de débris antiques, située à $2 \mathrm{~m}$ sous le sol moderne. Il y avait là une très importante masse de débris de marbre concassés, accumulés sous la forme d'un volume plan concave d'environ $3 \mathrm{~m}$ de diamètre sur $1 \mathrm{~m}$ de hauteur (fig. 2 et 3). Ce qui représente près de $2 \mathrm{~m}^{3}$ de matériaux. Une très faible partie, de la valeur de 0,02 à $0,03 \mathrm{~m}^{3}$, avait été évacuée, une heure avant notre

Le sanctuaire aurait pu être établi en souterrain en utilisant les différences de niveau du sol du quartier d'Aion, sur les limiles de la ville, à proximité d'une importante source qui reçut, dans le haut Moyen Age, le nom de Saint-Pierre.

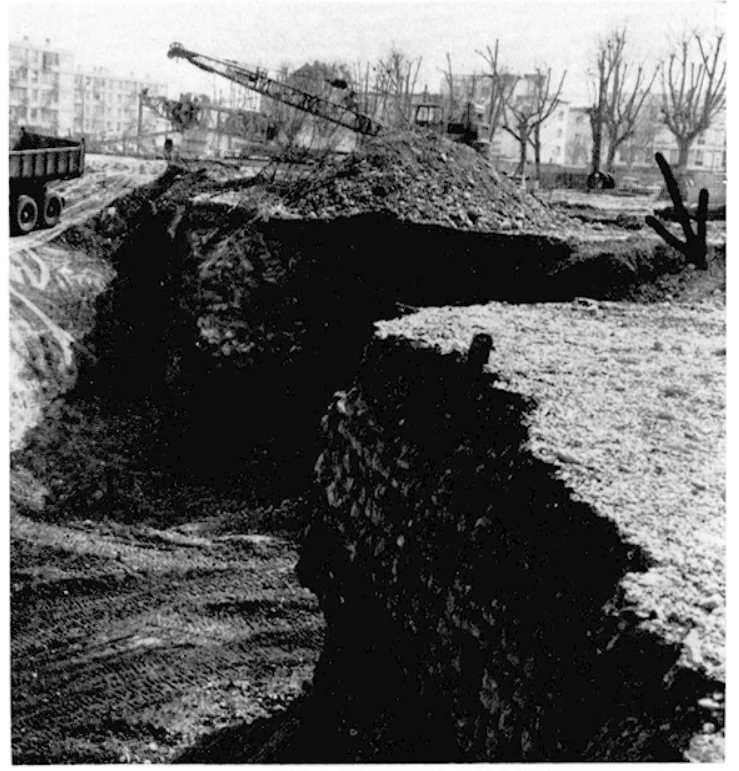

2 Le chantier de la poste, une portion du mur de l'enceinte intérieure a été dégagée. Dans cette zone aucune trace de constructions antiques, le rempart avait été repris entièrement au début du $x{ }^{e}{ }^{e}$ s. Le silo des fragments de marbre se trouvait à gauche.

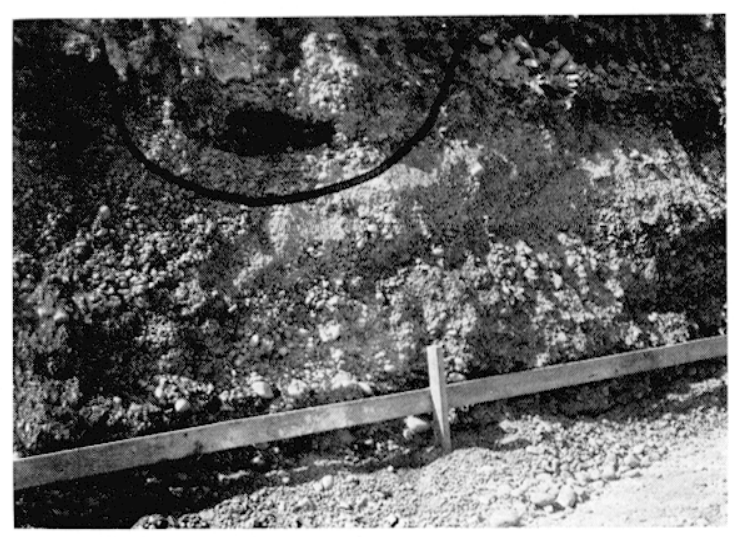

3 Silo de fragments de marbre dans la tranche du terrassement au moment de la découverte.

découvcrte, par les engins qui fròlèrent cette lentille et malgré toutes nos recherches aucun élément ne put être retrouvé.

Tous les fragments, représentant un total d'environ 3800 , sont en marbre, leur taille s'échelonne de la grosseur d'une noix à celle d'un poing. Ils furent recueillis, lavés et débarrassés dans de nombreux cas d'une gangue calcaire récente. Puis on procéda au triage : morceaux de sculptures et plaques 
dont certaines portaient des lettres gravées. Ces dernières furent ventilées uniquement en fonction de leurs caractères pétrographiques en quatorze groupes. On put dès ce moment faire plusieurs observalions. Cerlaines variétés de marbre ne donnaient que des plaques anépigraphes, portant quelques traces de mortier sur la face non polie; ceci prouvait que nous étions en présence de placages. Ces derniers, représentant au moins la moitié du volume total recueilli, excluaient la possibilité d'échantillons provenant d'une collection, mais prouvaient au contraire qu'à une certaine époque on avait soigneusement rassemblé tous les éléments en marbre rencontrés, peut-être dans la nécropole voisine, pour les concasser avant de les calciner dans un four a chaux ${ }^{5}$. De plus tous les fragments mis au jour appartenaient a l'époque gallo-romaine ; aucun élément plus récent ne s'était glissé dans ce silo. La présence de fines sculptures de taille modeste excluait un réemploi comme matériaux de construction, par exemple dans la base du rempart du Bas-Empire.

Arrivé à ce stade, il fut possible de tenter la reconstitution des plaques portant les inscriptions. Certaines variétés de marbre étaient particulièrement fragiles, de plus sous l'eflet des chocs la pierre avait éclaté dans son épaisseur; il devenait indispensable, avant d'aller plus avant, de recoller tous les fragments se raccordant. Après plusieurs essais nous sommes parvenus à un résultat satisfaisant en imprégnant les échantillons de diluant contenant $5 \%$ de colle avant de les fixer définitivement ${ }^{6}$. Il a été alors possible de commencer à déchiffrer les textes, travail qui facilita beaucoup le rapprochement des multiples fragments. Pour certaines inscriptions dont la face postérieure n'était pas plane, l'opération de collage a été effectuée sur un lit de sable.

5 Le même type de découverte s'est produit à Orange : A. Piganiol. Les documents cadastraux de la colonie romaine d'Orange, XVI ${ }^{\mathrm{e}}$ suppl. à Gallia, 1962.

6 Des essais furent entrepris avec l'aide des laboratoires Fismar à Strasbourg, que je tiens, ici, à remercier. On a utilisé une colle universelle et comme solvant un mélange d'esters à bas point d'ébullition.
Actuellement, quatre inscriptions ont pu être restituées dans leur presque totalité, l'une l'a été à moitié, quatre ou cinq autres n'ofirent que quelques lettres, l'ensemble représente plus de 1100 fragments. Il sera pratiquement impossible de restituer ces dernières : aucun élément s'y rapportant n'a été rencontré dans les publications antérieures; on peut supposer qu'en dehors des quelques fragments emportés à la décharge, le reste fut calciné à une haute époque.

1. Plaque de marbre blanc saccharoïde, l. : $0,86 \mathrm{~m}$, h. : 0,475 m, ép. : 0,0-15 m. L'inscription est entourée d'une bordure de $0,055 \mathrm{~m}$ de large. La face postérieure est plane. Toute la partie centrale de l'inscription porte les marques d'une profonde usure, la pierre fut certainement réutilisée dans un dallage ou un seuil (fig. 4 et 5).

$\mathrm{H}$. des lettres : 1 re ligne : $0,07 \mathrm{~m}, 2^{\mathrm{e}}: 0,065 \mathrm{~m}$, $3^{\mathrm{e}}$ et $4^{\mathrm{e}}: 0,055 \mathrm{~m}$.

Ce texte a deux lacunes, l'une très étroite à la première ligne entre le $a$ et le $o$ qui ne permet de placer qu'un $i$ ou un $t$ et, à la fin de la dernière ligne, où l'on retrouve une haste puis, après un espace sans trace de lettre, la partie supérieure d'un $c$ ou d'un $g$. Un point est placé au milieu de tous les $o^{7}$, le $n$ et le $d$ de Vindici sont liés et le $i$ est en monogramme dans le $c$. Les mots sont séparés par des points carrés. La forme des lettres correspond à la première moitié du $\mathrm{I}^{\mathrm{er}} \mathrm{s}$. Ce que ne contredit pas le sens du texte, facile à restituer malgré ses deux petites lacunes.

C(aio) Doio L(ucii) f(ilio) Tro(mentina) Pa[i]o / Arrecinae P(ublii) f(iliae) Sedalae | D(ecimo) Arrecino P(ublii) f(ilio) Pap(iria) Vinatci / Doia C(aii) f(ilia) Tertia f(aciendum) c(urauit)

Le nomen Doius n'est pas connu en Gaule, mais il est attesté ailleurs ${ }^{8}$. La tribu Tromentina

7 Yves Burnaxd, Chronologic des épilaphes romaines de Vienne, dans Rev. études anciennes (en abrégé : $R E A$, LXIII, 1961, p. 295 pense que les points all centre des o caractérisent l'époque julio-claudienne.

8 CIL V, 2524, Aieste; X, 4796, Teanum Sidicinum; XI, 5066 el 5095, Nevania; 5607, Arna. 


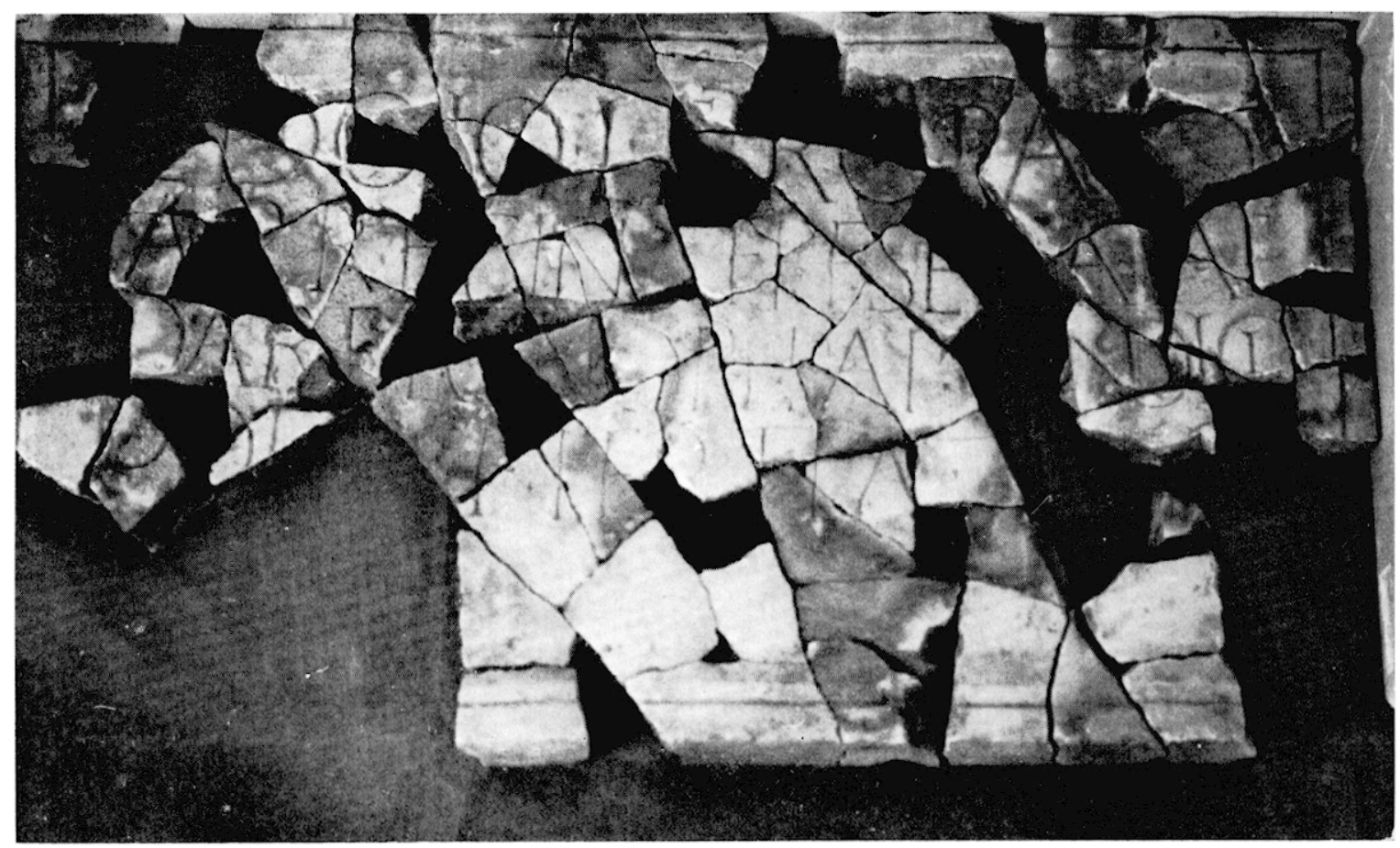

4

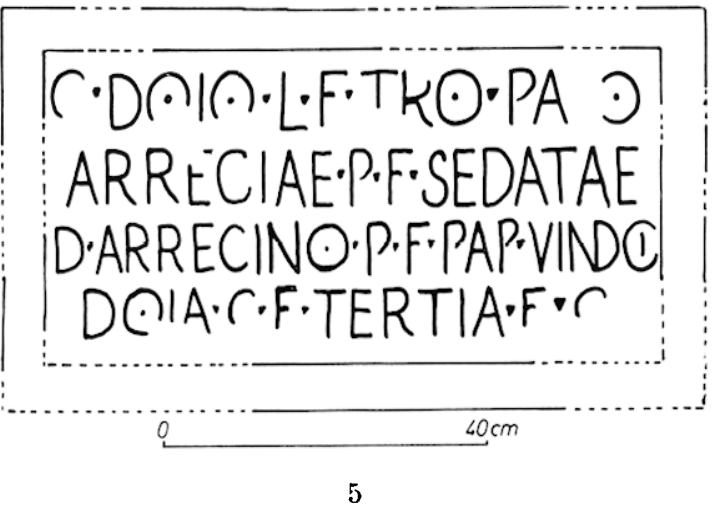

n'a pas été attribuée à une cité des Gaules ${ }^{9}$, les cognomina Paius ou Palus sont très rares ${ }^{10}$; le nom Arrecinus est plus connu, c'est le nom d'une gens romaine célèbre ${ }^{11}$. Beaucoup plus

9 W. Kuвırscheк, Imperium romanum tributim discriplum, Vienne, 1889, p. 272.

10 J. W. Schul.ze, Zur Geschichte der lateinischen Eigennamen, Berlin, 1904, rééd. 1968. - On retrouve le nomen de Paius, CIL VI, 5623; V, 1956.

11 CIL XIII, 3637, Arrecinus Clemens, consul en 73 ; Tacite, Hisloires, IV, 68 ; Arrecinus Gemellus, CIL XIII, 6821 .
4 et 5 Texte $n^{0} 1$, les dessins sont plus complets que les photos, ils ont permis d'utiliser de petites écailles de faible épaisseur. répandus sont les cognomina Sedala ${ }^{12}$ el Vindex ${ }^{13}$.

La tribu Papiria était celle des Narbonnais, mais il est fort possible qu'Arrecinus soit originaire d'Italie.

Arrecina Sedala et Arrecinus Vindex étaient frère et sceur, ils ont le même père Publius.

12 CIL XII, 793, Aix; P. Wullleumier, Inscriptions latines des Trois Gaules, XVII ${ }^{\mathrm{c}}$ suppl. à Gallia, 1963, 449, Saverne.

13 CIL XII, 515, Aix; 1967-2031, Vienne; 344, Cabasse. 


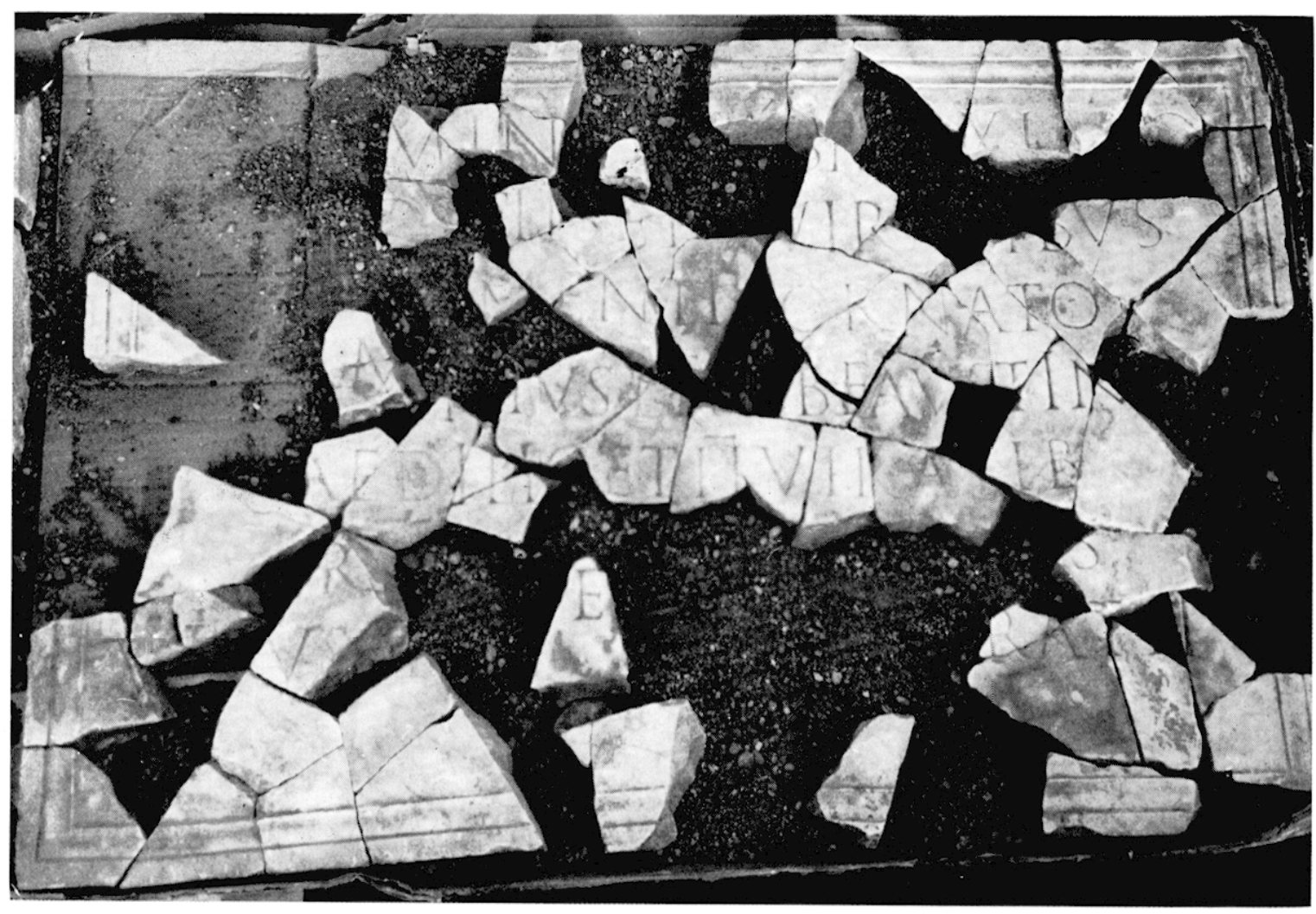

6

6 et 7 Texte no 2.

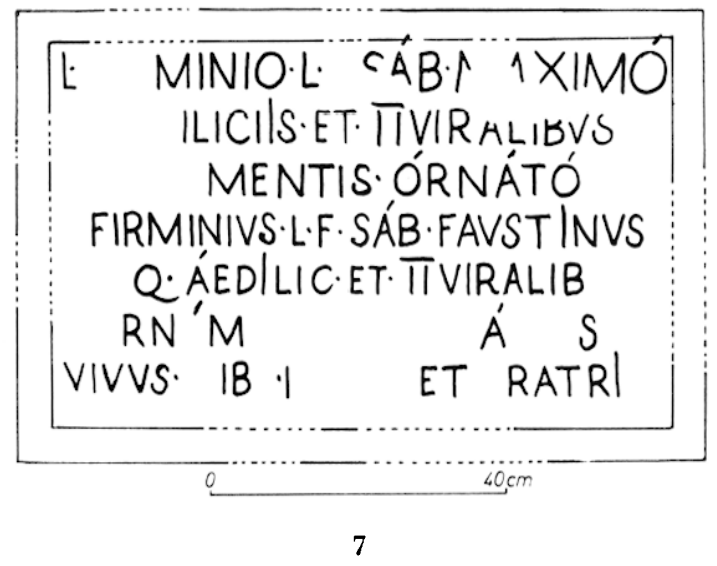

La dédicante Doia Tertia est la fille de Caius Doius et vraisemblablement d'Arrecina Sedala. Elle aurait élevé ce tombeau pour son père, sa mère, et son oncle Arrecinus Vindex.

2. Plaque de marbre dur, gris bleuté, I. : $0,93 \mathrm{~m}$; h. : $0,58 \mathrm{~m}$; petite bordure sur les quatre côtés de $0,045 \mathrm{~m}$, épaisseur irrégulière comprise entre $0,05 \mathrm{~m}$ et $0,08 \mathrm{~m}$ (fig. 6 et 7 ).

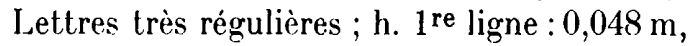
$2^{\mathrm{e}}: 0,042 \mathrm{~m}, 3^{\mathrm{e}}$ et $6^{\mathrm{e}}: 0,040 \mathrm{~m}, 7^{\mathrm{e}}: 0,036 \mathrm{~m}$. Un $i$ long au premier et au dernier $i$ de aediliciis, à Fauslinus et à fratri. Les accents sont bien marqués sur les voyelles longues. ce qui avec la symétrie des lignes permet de restituer ce texte dans sa totalité. La forme 
des lettres, en particulier la queue de la lettre $q$, s'allongeant sous la lettre suivante ferait penser à la première moitié du $\mathrm{i}^{\mathrm{er}} \mathrm{s}$.

L(ucio) [Fir]minio L(ucii) [f(ilio) Sjáb(atina) Maximó / [q(uaesloriis) aed $]$ iliciis.et.duumuira[l]ibus / [orna]mentis. órnáló / [ . . Fi ]rminius L(ucii) f(ilius) Sáb(atina) Faustin[u]s / q(uaestoriis) aedilic(iis).el.duumuiralib(us) । $[\dot{o}] r n[a ́ a] m[e n t i s$ orna $] \dot{a ́}[t u] s \quad /$ uịuus $[s] i b ̣[i]$ $f[e c i t]$.el. $[f]$ ratri

Il s'agit d'une épitaphe faite par Firminius Faustinus, dont nous ignorons le prénom, à son frère Lucius Firminius Maximus. Les deux frères appartenaient à la tribu Sabatina qui n'est pas connue en dehors de l'Italie; ils ont été l'un et l'autre honorés de la questure, de l'édilité et du duumvirat. Les fonctions municipales sont citées dans l'ordre direct, des exemples semblables sont connus en Gaule ${ }^{14}$. Aucune cité n'étant mentionnée on peut penser que les deux frères ont exercé leurs fonctions à Valence, ce qui était logique, avec son statut de colonie réelle. L'épitaphe de Tiberius Claudius Pius ${ }^{15}$, trouvée au siècle dernier dans la maçonnerie du rempart sud, était celle d'un décurion lyonnais pourvu des ornamenta du duumvirat ; decurionis Lugudini $\pi$ uiralib(us) ornamentis exornali ne témoignait nullement que la ville ait été régie par les duumvirs, attendu que les ornamenta duumuiralia mentionnés peuvent se rapporter à Lyon.

Le nomen Firminius n'est pas attesté en Narbonnaise ; un texte valentinois, reproduit par le GIL, d'après une lecture d'Allmer Firmi ... ${ }^{16}$ doit être lu Firmius et non Firminius comme il était supposé dans la Carle archéologique de la Drôme $e^{17}$ (fig. 8). Il existe

14 CIL XII, 4238, 4237, Réziers; XIII, 1900, 1921 , Lyon; $I L G N, 1$, vence.

15 CIL XII, 1750

16 CII, XII, 1762.

17 J. Sautes, Carte arch. Gaule romaine, Drôme, 1957 , p. 97. J'ai retrouvé cette inscription dans une écurie, au quartier de Saint-Gervais à Portes-lesValence. La fin de la deuxieme ligne est complete, il faut bien lire Firmius :

[El memoriae. ae[1/er]nae. L(ucii) Firmi / [M]axsimi. M(arcus) Firm[i/us] Valerianu[s!fra]tri incom!pa| r]abili.

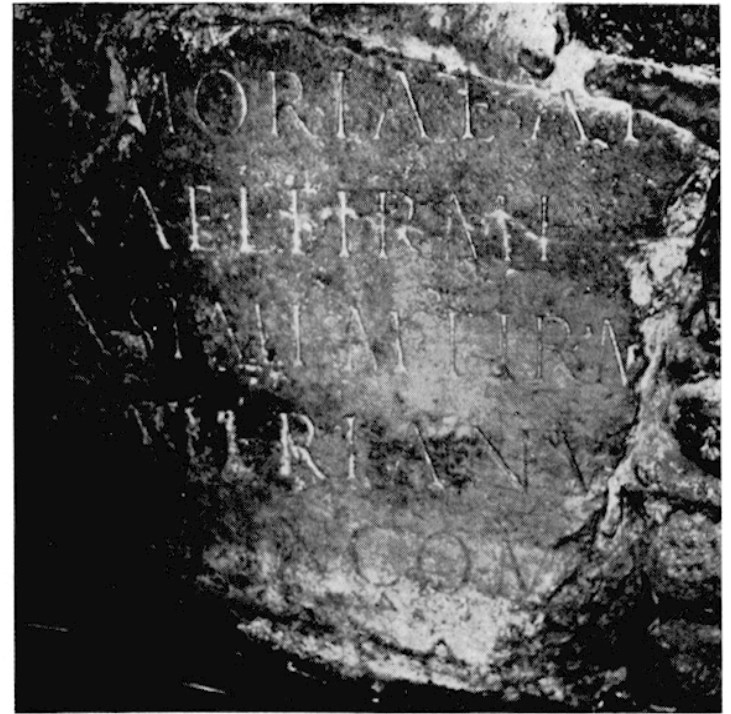

8 Inscription aujourd'hui à Beauvallon au quartier de Saint-Gervais, dans le mur d'une écurie, CIL XII, 1762.

un autre Firminius dans l'important lot des nouvelles inscriptions de Valence que nous signalons ci-après. En Gaule, on retrouve le nom de Firminius à Bordeaux et sur le Rhin ${ }^{18}$.

Les cognomina Maximus et Fauslinus sont répandus en Narbonnaise près de Valence, le premier se retrouve à Taulignan ${ }^{19}$, le second à $\mathrm{Die}^{20}$.

3. Plaque de marbre gris bleuté très tendre, l. : $0,65 \mathrm{~m}, \mathrm{~h} .: 0,65 \mathrm{~m}$, épaisseur irrégulière comprise entre $0,11 \mathrm{~m}$ et $0,07 \mathrm{~m}$. Une bordure très saillante de $0,06 \mathrm{~m}$ de large existe sur les quatre côtés délimitant un champ épigraphique carré et creux (fig. 9 et 10).

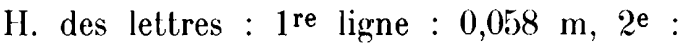
$0,037 \mathrm{~m}, 3^{\mathrm{e}}: 0,029 \mathrm{~m}, 4^{\mathrm{e}}: 0,028 \mathrm{~m}, 5^{\mathrm{e}}: 0,030 \mathrm{~m}$, $6^{\mathrm{e}}: 0,031 \mathrm{~m}, 7 \mathrm{e}: 0,042 \mathrm{~m}, 8^{\mathrm{e}}: 0,031 \mathrm{~m}$.

Les lettres sont irrégulières et un peu allongées pour les quatre premières lignes, elles semblent l'œuvrè d'un même lapicide. Il n'en est pas de même pour les suivantes qui mentionnent un nom par ligne et sont tres dissemblables entre elles. Ces différentes écritures et les signes de ponctuation variés :

18 CII. XIII, 627, 7519, 7654, 7971, 8401.

19 CII XII, 1711.

20 CIL XII, 1649. 


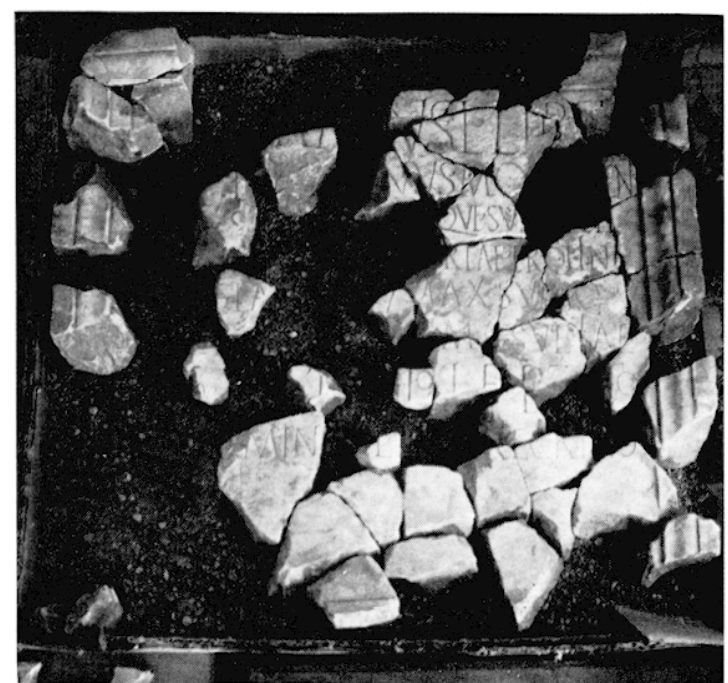

9

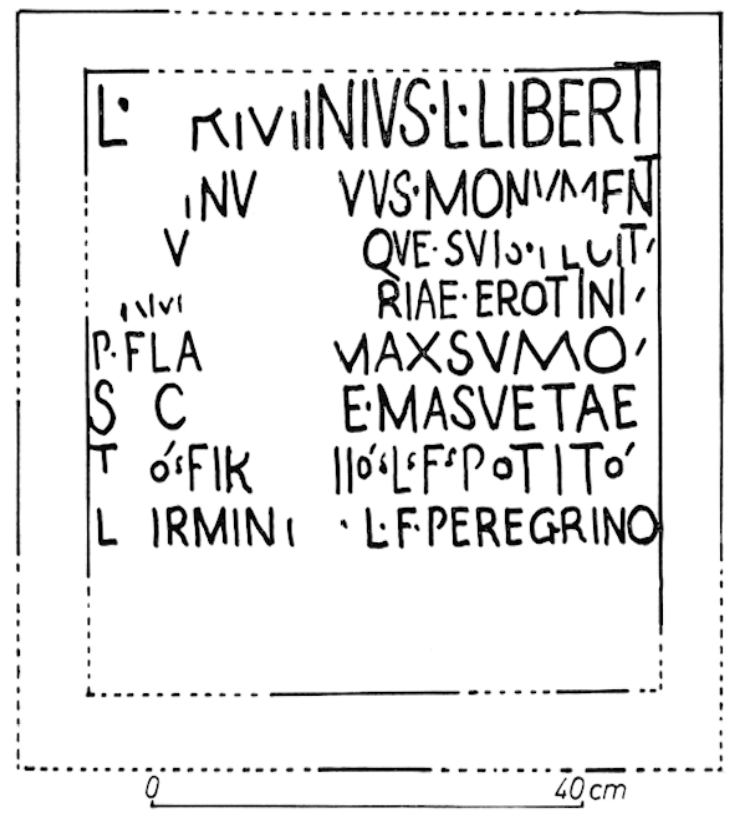

10

9 af 10 Texle $1^{\circ} 3$, le dessin donne l'étal définitif, un pelit fragment a été déplacé après la photo, il en est de même pour le texte 4.

points ronds, triangulaires, angulaires ou en forme de crosse, avaient fait penser au moment de la découverte à des inscriptions indépendantes. On peut remarquer qu'il reste, entre la dernière ligne et la bordure inférieure, un espace libre de $0,140 \mathrm{~m}$ de haut, ce qui aurait pu permeltre trois lignes de texte. I es $3^{\mathrm{e}}, 4^{\mathrm{e}}$ et je lignes se terminent à droite par un point en forme de virgule.

La première ligne peut se restituer facilement: L(ucius) Fi]!ṃinius. L(ucii) liberl(us). Un cognomen devrait suivre au début de la deuxième ligne, en complétanl [ui]uus, la lacune est de 6 a 7 leltres pour laquelle nous possédons les dernières lettres $n u[s$ et la base de deux hastes. Nous proposons la restitution avec quelques réserves de Rufinus, cognomen bien connu en Narbonnaise ${ }^{21}$. On aurait donc pour la deuxième ligne : Ruf inn s.ui] uus.monument(um), le $n$ et le $l$ sont liés en monogramme. La troisième ligne présente une lacune de 10 lettres environ pour laquelle nous possédons un $u$ qui se trouve sur le mème fragment que les deux hastes rencontrées à la deuxième ligne. En restituant Rufinus le $u$ ne pourra correspondre qu'à la troisième ou à la quatrième lettre du mot. Nous proposons Sepu[lchrum] que qui correspond très bien au sens de la phrase qui se termine par : suis fecit. La quatrième ligne est la plus difficile à restituer : le sens du texte réclame un nom, certainement féminin puisque nous avons un cognomen Erolini précédé de la terminaison... riae. Cette personne étant proche du dédicant il pourrait s'agir soit d'une fille, soit de la compagne de Firminius Rufinus. La difficulté réside dans le fait que la lacune est d'environ dix lettres ce qui nous oblige à trouver un nomen féminin d'au moins quatorze lettres. Pour nous aider nous avons en dehors de la terminaison deux éléments, très minimes, qui devraient se rattacher au début du mot, car ils figurent sur le même morceau de marbre que Fla[vioj de la cinquième ligne. Le premier appartient à la base d'un $e$ ou d'un $r$, le second à un $e$, $m$, ou $a$. Dans l'ouvrage de J. W. Schulze 22 nous n'avons trouvé qu'un nomen de plus de treize lettres, se terminant par ria ou rius, 
susceptible de combler la lacune : Vincensumaria ${ }^{23}$ que nous pouvons difficilement accepter. Une autre solution peut être envisagée, celle d'un personnage à double cognomen; il en existe quelques exemples ${ }^{24}$. Si nous adoptons cette hypothèse, Erolini deviendrait un petit nom de familiarité, il serait précédé du véritable cognomen et du nomen. Pour ce dernier on pourrait penser, si Erolini est bien une fille de Firminius Rufinus, qu'elle portait un nom identique à celui de son père ou dérivant. La restitution Firminiae nous offre bien un $r$ suivi d'un $m$ pour les troisième el quatrième lettres. Dans ce cas on n'aurait plus qu'une lacune de deux lettres pour le premier cognomen qui se termine par riae. Il en existe un, attesté à haute époque, Maria $^{25}$. Dans ce cas cette ligne pourrait se restituer : [Fi]?m[iniae. Ma]riae Erotini, avec deux $i$ longs pour le dernier mot. La cinquième ligne, d'une écriture large et plus classique donne un nom P(ublio) Fla[uio] Maxsumo, la symétrie interdit toute mention de filiation. A la sixième ligne un nom de femme $S[e] c[$ undia $]$. Masuetae. Les deux dernières lignes sont plus complètes, elles nous offrent deux noms d'hommes apparentés au dédicant. Pour la septième, les lettres sont plus hautes, par contre tous les $o$ ont un diamètre très réduit, certains sont accentués, les points séparatifs sont constitués par de petites crosses. Pour le prénom nous avons au début de la ligne un tout petit espace qui est limité à gauche par une haste et à droite par un $o$ accentué. Pour ce prénom très court, écrit en entier, commençant par une haste, nous proposons $T[i l] \hat{o}^{26}$. A la dernière ligne les lettres sont plus régulières, la forme des $g$ avec un appendice

23 CIL VI, 5623, gentilice formé d'après un nom de société.

24 CIL XII, 782, 2464, $2473 \mathrm{n}, 3706$.

25 Maria a été employé comme nomen el comme cognomen, pour ce dernier CIL XII, 1516, 1567, 2611, 2664 (Le Pouzini, 2873, 5955. Il existe une autre possibilité avec Viria, nom beaucoup moins répandu, un seul exemple de Virius utilisé comme cognomen, CIL XII, 1124.

26 Les exemples sont nombreux avec le prénom Tilus, CIL XII, 137, 344, 443, 453, 1262, 2425, 2873, 3473, 3496, 3553, 4074, 5813. courbe semble indiquer la fin du $\mathrm{II}^{\mathrm{e}} \mathrm{s}$. Nous proposons pour l'ensemble de l'inscription :

L(ucius) [Fi]rminius L(ucii) libert(us) । [Ruf] $]$ inu[s. ui] uus. monument(um) / [sep]u[lchrum]que suịs tẹcil / [Fi] rṃ[iniae. Ma]riae. Erotini / P(ublio). Fla[uio]. Maxsumo / $S[e] c[$ undia $]$ e. Masuetae / T Tit $]$ ó. Fir $[$ mi $]$ nio. L(ucii). f(ilio). Potitó / L(ucio) [F]irmini[o]. L(ucii). f(ilio). $[$ Pe]regrino

Ce texte écrit en plusieurs fois n'est pas facile à interpréter. Le fait de retrouver à la fin de l'inscription deux Firminius, fils de Lucius, l'auteur de la première partie de l'épitaphe, semble exclure l'hypothèse d'un collège funéraire. On penserait plutôt à un tombeau de famille où les noms se suivent chronologiquement aux décès. Le dédicant serait un affranchi, son cognomen Rufinus ne nous renseigne pas sur son origine. A la ligne suivante, un nom féminin qui pourrait être celui de sa fille; nous avons proposé avec des réserves : Firminiae Mariae Erolini. Cependant il n'existe aucune trace de lettre marquant la filiation. On pourrait aussi se trouver en présence de la compagne du dédicant portant un nomen très long dans le genre de Vincensumaria. Le cognomen Erotini est un nom d'origine grecque ${ }^{27}$. Les noms qui suivent au-dessous du texte primitif occupent chacun une ligne: Publius Flavius Maxsumus et Secundia Masıela; ils sont très fréquents en Narbonnaise ${ }^{28}$, le dernier cognomen est issu du nom gaulois Mansuetos ${ }^{29}$. Aucun lien de parenté n'étant indiqué sur l'inscription, on pourrait supposer que Secundia Masueta était la compagne de Lucius Firminius Rufinus. Dans ce cas il est étonnant de ne pas retrouver dans sa descendance des noms rappelant les siens. On pourrait également penser à une belle-fille. Le même problème se pose avec Publius Flavius Maxsumus qui

27 CIL XII, 520, 762, 4501, 4979.

28 Flavius, CIL XII, 165, 43I, 662, 682, 4819. Maxsumus, CIL XII, 1007, 1177, 1235, 4734, 5107, 5191. Secundia, CIL XII, 704, 2763, 2764; Masuela, CII. XII, 1998, 2884.

29 Mansuetus, CIL XII, 574, 1076, 1305, 2226, $2238,2266,2675,2677,3000,3380,3643,3719,3724$, 5189 . 


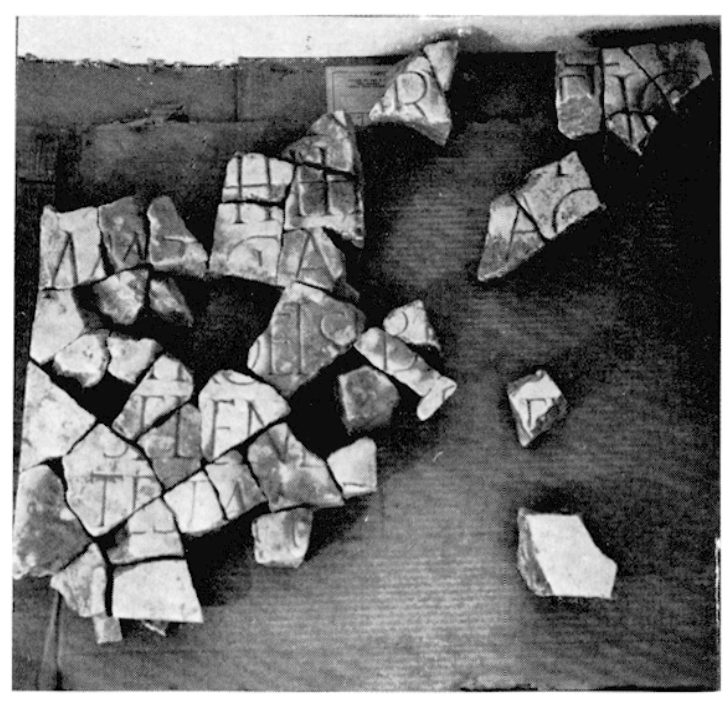

11

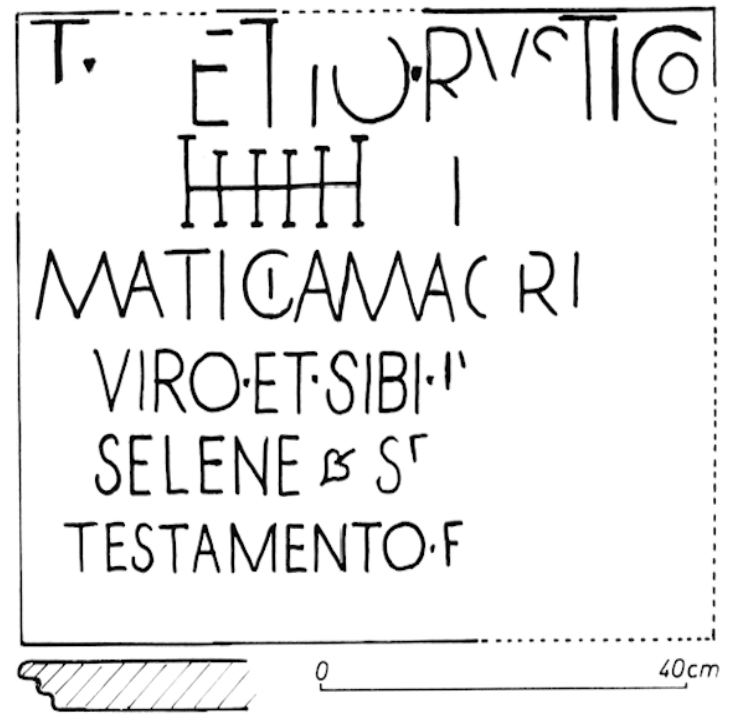

12

11 et 12 Texte $n^{\circ} 4$.

serait peut-être un gendre. Avec les deux derniers noms, qui occupent eux aussi chacun une ligne, nous sommes sur un terrain plus solide. La filiation est bien indiquée, il s'agit certainement des fils de l'auteur de la première partie du texte. Le second porte le même prénom Lucius, que son père, il devait, être le fils aìné, son cognomen Peregrinus est fréquent en Narbonnaise et à Lyon ${ }^{30}$. Il en est de même pour le cognomen du premier Politus ${ }^{31}$. Il est fort probable que Lucius Firminius Rufinus ait été affranchi par l'un des deux fròres Firminius, citoyens romains, inscrits dans la tribu Sabalina, connue par l'inscription précédente.

4. Plaque de marbre blanc-beige saccharoïde, l. : $0,76 \mathrm{~m}, \mathrm{~h}$. : $0,62 \mathrm{~m}$, le dessous est plan. parallèle au champ épigraphique qui occupait toute la surface, il n'y a pas de moulure. Par contre, un chanfrein mouluré a été pratiqué très régulièrement sur les quatre còtés, au détriment de la face postérieure, ép. : 0,050 m (fig. 11 et 12 ).

30 Peregrinus, (:IL, XII, 丈56, 3053, 3179, 3233, 3331, 3428, 4607, 4913, 5106.

31 Potilus, C:IL XII, 2210, 2450, 4247, 4483, $5001,5154,5211$.

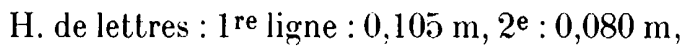
$3 \mathrm{e}^{\mathrm{e}}: 0,076 \mathrm{~m}, 4^{\mathrm{e}}: 0,068 \mathrm{~m}, 5^{\mathrm{e}}: 0,064,6^{\mathrm{e}}:$ $0,053 \mathrm{~m}$.

A la première ligne les $t$ dépassent la hauteur des lettres, le $c$ et le $o$ forment un monogramme, également pour le $c$ et le $i$ de la troisième ligne, un $l$ à longue hampe pour la quatrième. $\mathrm{Au}$ milieu de la cinquième ligne de cette inscription parfaitement symétrique, une hedera. Des traces de peinture rouge sont encore apparentes dans le creux des lettres.

T. L Lelio . Rustico ! IIIIII $[u] i[r(o)]$ / Malicia . Macri[na / uiro. et. sibi. i[ussit]/ Selene. $\operatorname{se}[r(u a) . e x\} /$ testamen $[l] o . f[a c(i u n-$ dum) $\operatorname{cur}($ avit)]

La restitution de ce texte est facilitée par la très grande symétrie de l'inscription. Selene qui porte un nom grec ${ }^{32}$ a élevé à son maître le sévir Titus Letius Rusticus ${ }^{33}$, confor-

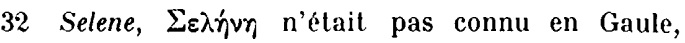
il a été porté par la fille d'Antiochus (CicÉrov, In Verrem actio, 4, 27j et la fille de Marc Antoine !SuÉtoNe, Caligula, 26.

33 Ce nomen est celui d'un sévir de Nîmes, CIL XII, 3245, Lucius Letius Marullus, le cognomen Rusticus est très connu en Narbonnaise, CIL XII, 684 Arles, 1377 Vaison, 3404 et 3283 Nìmes, 4122 Saint Gilles, 4935 Narbonne, 5412 Vienne; ILGN, 186 Orange, 421 Nîmes, 364 Genève. 


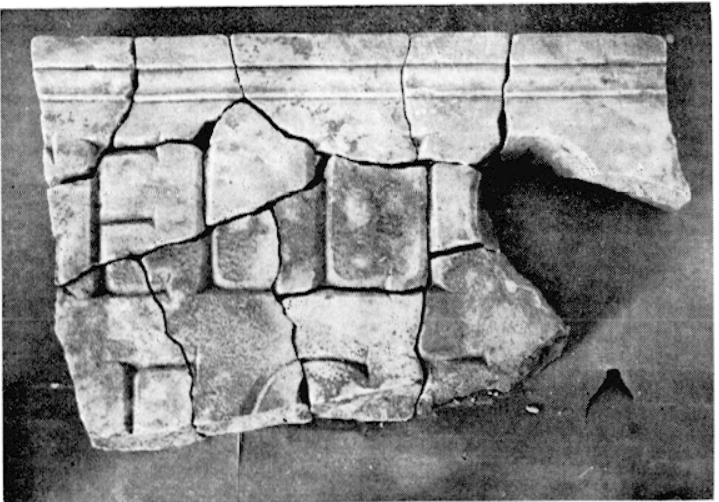

13 Le nomen Gellius du texte no 5 .

mément aux ordres de sa femme Maticia Macrina ${ }^{34}$, un tombeau suivant les prescriptions du testament. Ce qui pourrait laisser supposer que Malicia Macrina ait suivi de peu son mari dans la tombe. Quelques particularités se rencontrent cependant: à la deuxième ligne la symétrie ne permet pas d'ajouter les trois lettres aug pour compléter sévir augustal, fonction exercée vraisemblablement à Valence ${ }^{35}$. Le mot uiro à la troisième ligne écrit pour coniux est connu, on rencontre plusieurs exemples en Narbonnaise ${ }^{36}$; il en est de même pour le mot serva, moins employé que verna ${ }^{37}$.

5. Plaque de marbre gris-jaune, très mutilée, l. supérieure à $1 \mathrm{~m}, \mathrm{~h}$. au moins $0,50 \mathrm{~m}$, l'épaisseur irrégulière de 0,05 à $0,08 \mathrm{~m}$, une bordure semble avoir existé sur les quatre còtés, larg. : $0,038 \mathrm{~m}$ (fig. 13).

H. des lettres : $1^{\mathrm{re}}, 2^{\mathrm{e}}$ et $3^{\mathrm{e}}$ lignes : $0,10 \mathrm{~m}$, $0,08 \mathrm{~m}$ pour une ligne inférieure.

I.e premier groupe (a) nous donne un nom Gellius, qui semble se répéter dans une ligne

34 Le nomen Maticia est vraisemblablement d'origine celtique CIL XII, 1011, Glanum, Malucia, ILGN, 230, Luc-en-Diois. Malicius, à Lyon, CIL XIII, 2207. Le cognonem Macrina est beaucoup plus répandu, CIL XII, 2682 Alba, 2203 Saint-Aupre, Macrinus, CIL XII, 1743 Montélimar.

35 Deux sévirs étaient déjà connus à Valence, CIL XII, 1751, Caius lulius Aper, et Sextus Valerius Amonoenus, A. Blaxc, Gallia, XXII, 1964, p. 276. 36 CIL XII, 467, 1430, 1902, 2813.

37 CIL XII, 4793. inférieure (c) Gellius ou Gellia; ce nom appartenant à une gens romaine ancienne est connu en Narbonnaise ${ }^{38}$.

Dans le groupe (b) qui appartient à la première lignc on pourrait penser à $[F, T r] o$. M. . , la lettre $m$ étant la première du cognomen et le o peut-être la fin de l'abréviation de la tribu Tro(mentina), retrouvée dans l'inscription no 1 .

Dans le groupe (c) au-dessous de Gel : $\overline{I I}$ vir.

Les trois lettres du groupe (d) : sex appartiennent à une ligne inférieure. On pourrait penser au prénom Sextus où, vu l'espace relativement large entre le $s$ et le $e x$, à une formule déjà connue à Valence [duımuiralibus ornamenli]s ex[ornatus $]^{39}$.

6. Une quarantaine de petits fragments sont issus d'une plaque de marbre très dur gris bleuté, épaisseur régulière $0,0: 3 \mathrm{~m}$, le champ épigraphique est entouré d'une bordure en relief de $0,07 \mathrm{~m}$ de large. Les quelques lettres restituables sont encore recouvertes d'une couche de peinture adhérente rouge vif. Le pigment se présente au microscope sous la forme de minuscules bâtonnets.

M(arco) [..]o. M(arci) . [f(ilio) ...] hauteur des lettres : $0,07 \mathrm{~m} \ldots m$...s $t$... hauteur des lettres : $0,06 \mathrm{~m}$

$y$ Petite plaque de marbre blanc, ép. : 0,018 m, bordure plate $0,045 \mathrm{~m}$ de large, lettres fines : $\ldots a \ldots$. . : $0,05 \mathrm{~m}, \ldots s \ldots$ h. : $0,045 \mathrm{~m}$

8. Plaque de marbre blanc-jaune, pas de trace de bordure.

$[\ldots] Q . F \cdot P[o l(l i a) ? \ldots$ h. des lettres : $0,05 \overline{\mathrm{s}} \mathrm{m}$.

Ces inscriptions funéraires paraissent, à l'exception du texte no :3 qui semble plus récent, assez homogìnes. On peut les dater

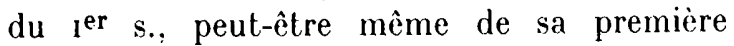
moitié : dédicace au datif, forme des lettres et points au milieu des o pour le texte $n^{\circ} 1$.

38 CII. XII, 1410, 1882, 1883, 1886, 1887, 1889, $2842,2927$.

39 CIL XII, 1750. 


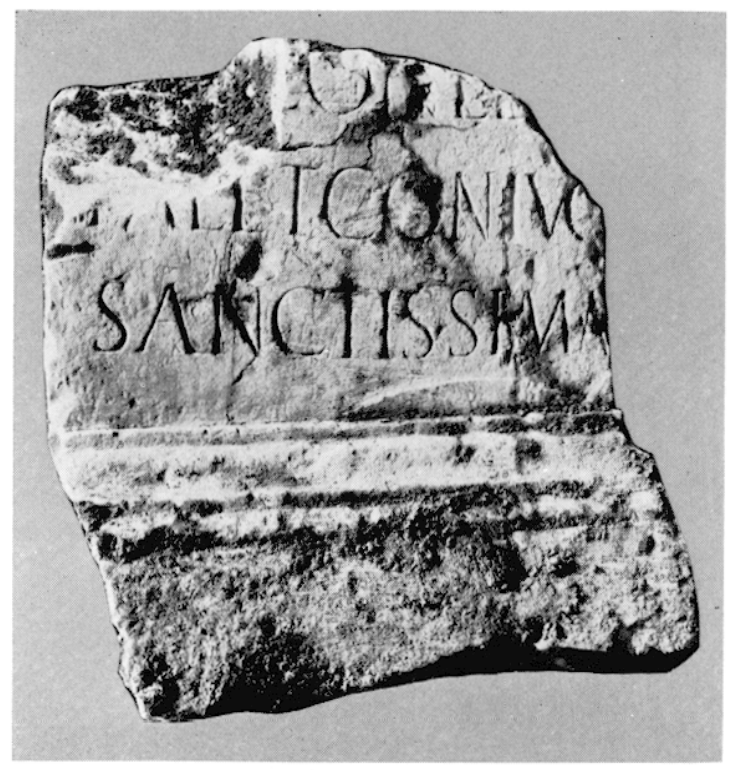

14 Fragment calcaire de la Porte-Neuve.

Les personnages mentionnés Caius Doius et peut-être Gellius sont répartis dans la tribu Tromentina, les deux frères Firminius dans la tribu Sabalina, Decimus Arrecinus Vindex dans la tribu Papiria. Leur nom n'est pas celtique et se retrouve plus souvent en Italie qu'en Gaule. On pourrait penser que ces derniers sont des citoyens romains venus à l'origine de la colonie de Valence et qui conservèrent, selon l'usage, leur tribu d'origine jusqu'à leur mort. Une seule mention, hélas fort douteuse, au no 8 , de la tribu Pollia, qui semble avoir été celle des Valentinois ${ }^{40}$. On rencontre également par deux fois la fonction de duumvir. Cela tend à confirmer l'hypothèse ${ }^{41}$ que Valence, colonie de citoyens romains, était régie par des duumvirs.

9. Fragment de stèle funéraire en calcaire, incomplète en haut, écornée sur les trois autres còtés, découverte à Valence, en 1969 , place de la Porte-Neuve, au cours de terrassements pour la construction du passage souterrain est de la place de la République. Cetle pierre avait dû être réutilisée dans la base du rempart du Bas-Empire, h. : $0,70 \mathrm{~m}$,

40 A. Bianc, Acles Congris nat. des Soc. Savantes, Lyon. 1964, p. 87.

41 A. Allmer, Bull. Soc. arch. Dröme, VIII, 1874, p. 20 . larg. : $0,62 \mathrm{~m}$, ép. : $0,40 \mathrm{~m}$ (fig. 14).

Le texte incomplet correspond aux trois dernières lignes. H. des lettres : $0,08 \mathrm{~m}$ ... conlb[er]/lae el coniug[i] / sanclissima[e]

Le i de conl( $i$ berlae se trouvait certainement à l'origine en monogramme avec le $\mathrm{l}$. La partie supérieure devait porter le nom du dédicant et celui de sa vertueuse épouse qui était sa coaffranchie ${ }^{42}$.

10. Petit fragment de marbre, incomplet en haut, à droite et au bas, larg. : $0,130 \mathrm{~m}$, h. : $0,085 \mathrm{~m}$. ép. : 0,03 . Une petite moulure au dos ferait penser à la réutilisation d'un couvercle de sarcophage. Mise au jour à Valence, dans des terrassements, près du faubourg Saint-Jacques, à l'est de la ville. Le texte incomplet sur deux lignes, les lettres de très basse époque sont presque effacées, hauteur irrégulière de 0,015 à $0,025 \mathrm{~m}$ (fig. 15 et 16).

... ini via iii k.(a)l(endas)s[eplembres... Feli]/ ce v(iro) cl(a)r(issimo) con[sule...]

Il est bien difficile de reconstituer les premiers mots de ce texte liès à la partie supérieure de cette épitaphe chrétienne. Elle devait mentionner le nom et l'âge du défunt. On peut, toutefois, en déduire la date du décès au 28 aoùt 511 , année du consulat de Flavius Félix ${ }^{43}$.

II. INSCRIPTIONS ÉTRANGÈRES ¿̀ LA CITÉ de Valence

a) Cilé de Saint-Paul-Trois-Châteaux.

11. Pierre molasse tendre, retaillée pour être incorporée dans la voûte de la cave d'une vieille maison aujourd'hui restaurée, près de l'église romane de Clansayes (Dròme), 1. : 0,45 m, h. : $0,16 \mathrm{~m}$. Cette pierre porte sur sa face apparente une inscription en creux rétrograde, profonde et fort mutilée, peu lisible, h. des lettres : $0,028 \mathrm{~m}$ (fig. 17 et 18).

... Ino . L(ucii) . f(ilio) . VeTerano $R[\ldots$ un point au milieu des $o$.

Ce texte très mutilé fait penser à celui d'un

42 On retrouve à Vienne, CIL XII, 2009, une mention similaire colliberlae et coniugi carissimae.

43 On a découvert à Vienne quatre épitaphes contemporaines, CIL XII, 2063, 2064, 2065, 2066. 


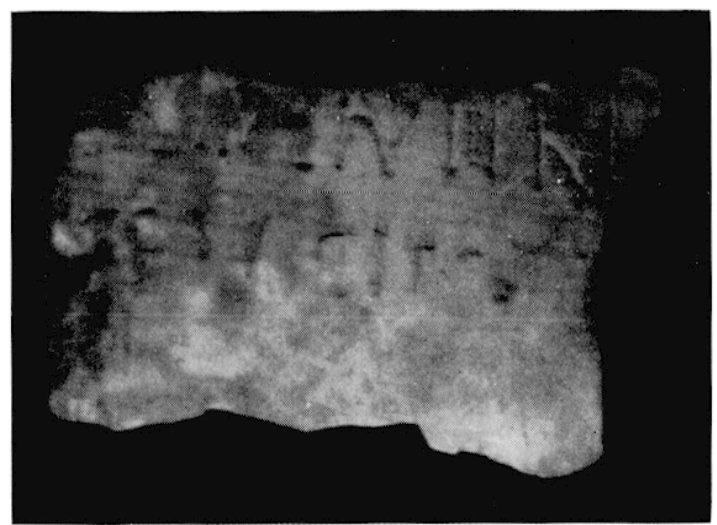

15

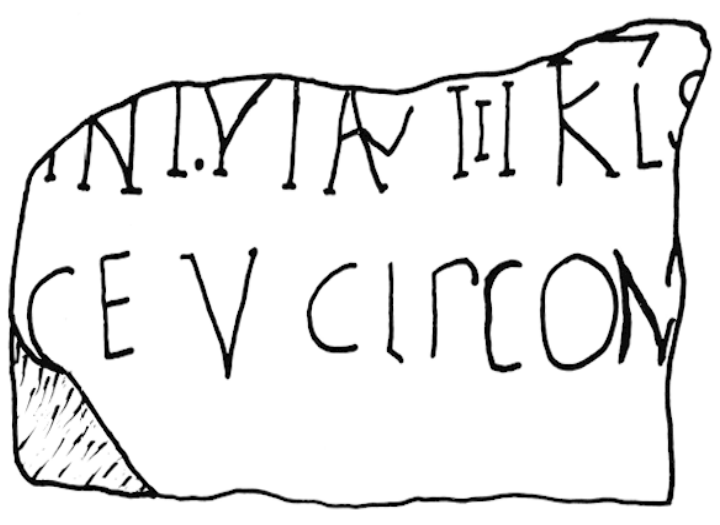

16

15 et 16 Fragment de marbre portant un texte funéraire chrétien.

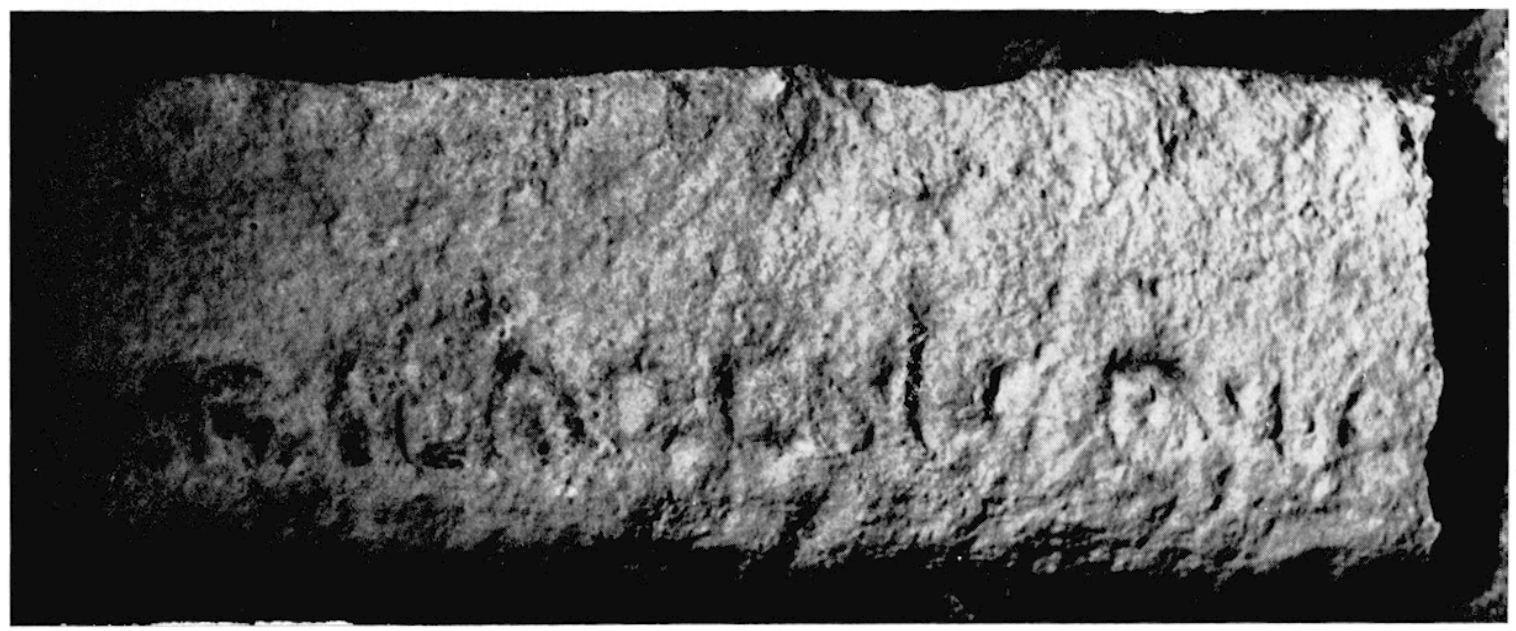

17

NOLFVERAMORI

18

grand poinçon. On pourrait être en présence de la partie épigraphique d'un moule pour tuyaux de plomb, la longueur du texte, la hauteur des lettres correspondent. Ces conduites avant leur façonnage et leur soudure par martelage se présentaient sous la forme d'un rectangle de métal, très allongé. On peut supposer que le moule était confectionné à même le sol à l'aide d'argile dans lequel était enchassée la pierre porlant en creux la marque rétrograde. Cependant le texte de Clansayes ne permet pas d'être affirmatif. On se trouve en présence de noms au datif, ...no et Veterano, en général les noms de plombiers sont écrits au nominatif ou au génitif. Le personnage mentionné, fils de Lucius, porte un nomen finissant par no et pour cognomen Velerano ${ }^{44}$ qui n'a été rencontré jusqu'à présent sur aucune estampille de tuyaux de plomb.

$\mathrm{Au}$ cours des recherches pour la rédaction de la Carle archéologique du déparlement

44 Veteranus, à Saint-Pierre-aux-L.iens, dans le Tricastin, CIL. XII, 1739. 
de l'Ardèche ${ }^{45}$, il a été possible de relire et de compléter quelques textes publiés au siècle dernier.

\section{b) Cité de Vienne.}

12. Arras, près de l'église, fragment de plaque de marbre, découvert en même temps que l'épitaphe de Placidia $^{46}$, portant une inscription avec des lettres peu régulières, incomplète à droite et en bas. Aujourd'hui perdu ${ }^{47}$.

tin hoc $l[$ umulo $]$ / requiesci l in $p a] / c e$ bone nemo[riae] / Gralus qu[i uixil] / plus m[inus annos ...]

Il s'agit d'un texte chrétien de très basse époque, la formule plus minus ne vient en usage qu'après $510^{48}$. Un type de faute classique au $\mathrm{vi}^{\mathrm{e}}$ s., nemoriae pour memoriae. Le nom Gralus est latin ${ }^{49}$.

c) Cilé d'Alba.

13. Rosières (canton de Largentière, Ardèche), lieu-dit mas Gradet, linteau calcaire portant une inscription en lettres monumentales sur trois lignes. La découverte est ancienne. En 1746 , M. Baudet qui avait vu la pierre adressa une copie de sa lecture à Esprit Galvet à Avignon. Un échange de correspondance suivit ${ }^{50}$, qui permet en la dépouillant d'avoir aujourd'hui des précisions, qui échappèrent en partie à Hirschfeld lors de la rédaction du CIL XII ${ }^{51}$. D'après la description de l'époque, la pierre mesurait 7 pieds, 10 pouces et 6 lignes de longueur soit $2,55 \mathrm{~m} ; 1$ pied, 10 pouces, 6 lignes soit $0,61 \mathrm{~m}$ de hauteur et 1 pied, 1 pouce, 6 lignes d'épaisseur soit $0,365 \mathrm{~m}$. Elle comportait trois lignes d'écriture les lettres avaient 2 pouces, 8 lignes soit $0,067 \mathrm{~m}$ de hauteur. Le champ épigraphique

45 A. Blaxic, Carle archéologique de la Gaule romaine, département de l'Ardiche, fasc. XV, 1975. 46 CIL XII, 1798.

47 Abbé Garxonier, Notice sur Eclassan, publiée en partic dans Revue du Vivarais, 1938-1939, p. 45.

48 LE Blant, Insc. chrét. de la Gaule, I, Paris, 1856 , p. $x$.

49 Gralus, CIL XII, 1307, 1310, Vaison; 1954, 1984, 2017, Vienne; 3087 Nimes.

50 Avignon, bibliothèque municipale, ms Calvel, III, fo 90,129 ; Marseille, bibliotheque municipale ms. Calvet, 1508 , p. 115.

51 CIL XII, 2718. était encadré en haut et en bas par deux moulures qui occupaient la moitié de la hauteur totale de la pierre. Elle semblait intacte, cependant les trois lignes d'écriture étaient manifestement incomplètes à droite, la deuxième ligne commençait en retrait de 4 ou j lettres par rapport aux deux autres. Ia dernière lecture dans le manuscrit le plus récent qui n'avait pas été utilisée donne la restitution suivante :

.M. Fanio Mf Voll Basso Fabio Valeriano cos prae... / prouinc Pannoniae inferioris curatori prou... / Misiae inferior comiti augustorum $P$...

Vers 1780, Jean-François Séguier s'intéressa à cette inscription, grâce aux estampages dc Flaugergues et de Taulèle, il fit une nouvelle lecture $^{52}$. Entre temps, la pierre avait été amputée de sa partie gauche "pour faire une pierre à huile»!

... asso Iabio Vaiiriano cos prai . . / . . oniai Iniirioris curaiori opir. . / . ouiiii auousiorum pariiiio aiixi...

Au début du $x x^{e}$ s., une dernière lecture fut faite sur l'extrémité droite de la pierre, qui avait échappé seule à la destruction ${ }^{53}$.

... iria no cos pra.. I . . ura iori opir... /

... um pariiii cai $i x$

Ces anciennes lectures permirent à Hirschfeld $^{54}$ de restituer la partie gauche de cette inscription aujourd'hui perdue.

M. [ I ja[ll]io. M.f. Voll. Basso [F]abio Valeriano cos.prae[fecto aerarii...j/ prouinc Pannoniae inferioris curatori oper(um) [publicorum...] / Mysiae inferior comiti augustorum Parthicae $\exp [$ editionis...]

En 1782, on découvrit au château de Saourné (Saumée), près de Joyeuse, à quelques kilomètres du mas Gradet, un fragment d'inscription. M. Taulèle qui habitait le pays adressa à Séguier ${ }^{55}$ une copie avec ce commentaire :

52 Jean-François Séguier, B. N. Paris, $m s .13 .816$.

53 Copie prise par Eugène Dubois, ancien magistrat à Thueyts, d'après RocchıEr, Hisl. du Vivarais, I, p. 122.

54 Commentaire au CIL XII, 2718.

55 J.-F. SÉguier, op. cil. 


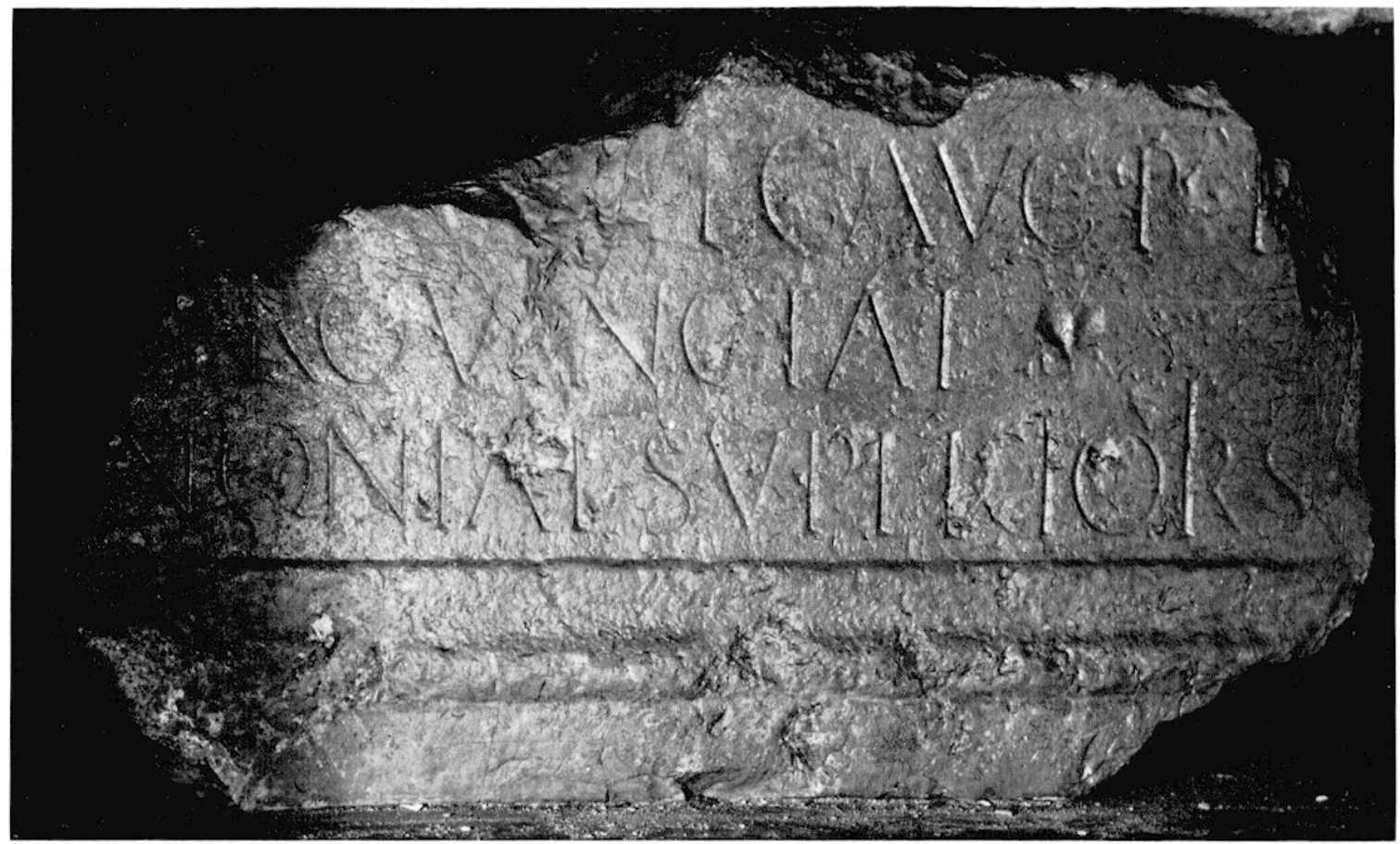

19 Fragment de linteau aujourd'hui au château d'Aubenas, CIL XII, 2719.

"elle a beaucoup de rapport avec celle que je vous ai adressée ».

...iig aug $p p \ldots / \ldots$ prouinciae ... $/ \ldots$ noniae superiors 56

Disparue peu de temps après sa découverte, elle ne fut retrouvée qu'en septembre 1957 par M. Robert Saint-Jean ${ }^{57}$ et transportée au château d'Aubenas où nous avons pu l'étudier (fig. 19). Il ne fait aucun doute que cette dernière inscription complètait celle mise au jour, en 1746, au mas Gradet. Mommsen l'avait pensé et il rapprocha les deux pierres pour tenter de restituer le texte primilif ${ }^{58}$.

Le personnage mentionné Marcus Iallius Bassus est connu, par une inscription de

56 Cill XII, 2719.

57 Gallia, XVIII, 1962, p. 375, 376 a fig. 20.

58 M. Iallio M. f(ilio) Volt(inia) Basso Fabio Valeriano $\operatorname{co}(n) s$ (uli) prae $[f(e c t o)$ aer (ari) . . .le $] g(a l o)$ aug(usti) pr(o)pr(aelore) I provinc(iae) Pannoniae inferioris, curatori oper(um) (publ(icorum) leg(alo) augg pr(o)pr(aelcre)] provinciae / Mysiae inferior(is) comili augustorum Parlhicae exp[ed(ilionis) leg(alo) augg pr(o)pr(aetore) provinciat Pan]noniae superior $(i) s$
Rome ${ }^{59}$ : c'est la dédicace d'un monument élevé sur un terrain assigné à cet effet par Iallius Bassus et Commodus Orfitianus, sous le règne des empereurs Marc-Aurèle et Vérus, le 15 décembre de l'an 161 . Une autre inscription de 'Troesmis dans la Mésie inférieure. actuellement Iglitza ${ }^{60}$, le montre gouverneur de cette province sous les mêmes empereurs, ce qui vient confirmer un autre texte mutilé de Bela Slatina ${ }^{61}$.

59 CIL, V1, 1119 b, Locus. adsignalus. ab / Iallio Bass\%. el / Commodo Orfitiano / cur. oper. publ cu. I cur / M. Caecilio. Alhenaeo / M. Valerio. Midia / I. Aelio Amphilale / dedic. IVIII. L. Lan / auguslis. n / Antonino. III. et. Vero. II. Cos.

60 ClL III, 6169, P]ro. sal. imp. Anl / et. Veri. aug. V. $\overparen{M a} c /$ Ialli. Bassi. leg. $\overparen{a u g}$ / pr. pr. Marli. Veri. leg / aug. P. Ael. Quintianus / Magni fil / leg $\checkmark M$ Ael Qu.....anl ....otsc c. m el... posuit.

61 CIL III, 12387, Sarjapidi. pro sal imperalol rum] caesarum au!ly M. Aureli An/to]nini. $\overline{e t}$. L. Aureti. Veri $\bar{i}$ el Faustinae I aulg.liberq.eorum [templum cum siglnis. M. Ialli. Bass. Lel!. auy. pr pr in / ch]oanti. consummanti [..ll]eg. $p r[\ldots$ 
I.'inscription perdue du mas Gradet ajoute considérablement à ce qu'on savait sur ce personnage important : on ne lui connaissait que ces deux noms, elle lui en donne deux autrcs, ceux de Fabius et de Valerianus qui peuvent provenir de sa famille maternelle. Elle le dit inscrit dans la tribu Voltinia, celle des Helviens, ce qui avait autorisé Hirschfeld à penser qu'il était originaire de l'Helvie et que le monument d'où provient l'inscription avait été élevé dans son pays natal. Il était tentant d'essayer de compléter les lacunes, en particulier celles concernant la série des honneurs en rapprochant tous les éléments dont on pouvait disposer du fragment qui nous était parvenu. L'examen de ce dernier a permis de faire quelques constatations nouvelles : le calcaire a grain dur ne se taillail pas de façon uniforme. Le lapicide a eu des difficultés pour graver aussi profondément les horizontales que les verticales. De sorte qu'avec l'usure les traits verticaux sont restés beaucoup plus apparents, ce qui explique les lectures du xvine s. La deuxième ligne est complète à droite, elle finit en retrait de cinq lettres par rapport aux deux autres qui l'encadrent ; cette particularité avait déjà été relevée par Calvet sur la partie gauche. A l'aide d'un puissant éclairage frisant il a été possible de lire à la première ligne la trace du bas d'une lettre formant un angle d'environ $40^{\circ}$, ce qui pourrait correspondre à un $u$, un $n$ ou un $m$; après un court espace qui ne pouvait être occupé que par un $i$, on rencontre la base d'une lettre courbe $c$ ou $g$, l'espace d'une lettre, puis leg aug $p^{\mathrm{r}} p(\mathbf{r})$. A la deuxième ligne : prouinciae. A la troisième ligne on lit ... noniae superioris, le $r$ et le $i$ sont liés.

Cette inscription paraissant parfaitement symétrique, on peut adopler, comme hypothèse, qu'à l'origine les trois lignes du texte étaient gravées sur deux linteaux monolithes de même longueur. On devrait ainsi retrouver, en comparant les lectures de la moitié gauche, environ 40 signes ou lettres pour la première et la troisième lignes de la moitié droite et environ 36 pour la seconde. Précisément, cette dernière ligne parait la plus facile à restituer; on en connait le sens depuis Iommsen : expeditionis leyalo augustorum duorum propraetore prouinciae Pannoniae superioris, mais on ignore dans quelle mesure la titulature des différents postes mentionnés a été abrégée. En comparant les données conservées, on constate que legalo Augustorum duorum propraetore a été abrégé : leg auggpr pr, mais que prouinciae est, soit écrit en toutes lettres, soit amputé de la désinence iae; expeditionis a pu être écrit en entier soit abrégé exped; nous aurions donc suivant le cas, 46,43 ou 38 signes ou lettres. La restitution de la deuxième ligne est également facile : oper [um publicorum leg augg pr pr]prouinciae, ce qui nous donne 33 signes ou lettres et nous permet d'adopter la troisième hypothèse pour la dernière ligne plus longue de 5 lettres ou signes, soit : exp ${ }^{\lceil e d}$ leg augg $\mathrm{pr}^{\mathrm{pr}}$ prouinc Pan noniae superioris. On constate devant cette concordance que la pierre de droite devrait avoir quelques centimètres de moins que celle de gauche. La partie la plus difficile à compléter reste la lacune de la première ligne. Différentes propositions peuvent être offertes, l'une paraît très vraisemblable : elle consiste à compléter prae en prae[tori] et à penser ensuite à une légation de légion en Pannonie supérieure. J. Fitz a précisément apporté la preuve ${ }^{62}$ qu'un cursus honorum tel celui de Iallius Bassus a comporté cette fonction de commandant d'une légion de Pannonie supérieure. Nous aurions dans ce cas le choix entre trois légions : la $I$ Adiutrix Pia Fidelis, la $X$ Gemina Pia Fidelis et la $X I I I I$ Gemina Martia Victrix. La lacune correspondant à environ 25 lettres ou signes, on ne peut adopter que la XIIIIe légion en abrégeant Geminae Marl Vicl, ce qui nous donnerait pour la première ligne prae[tori leg leg XIIII Geminae Mart Vicl] leg aug $p^{\mathrm{r}} p^{\mathrm{r}}$. L'abréviation Vicl pour Vitricis est confirmée par les traces de bas de lettres visibles sur la pierre en particulier le $\boldsymbol{u}$ et le $c$.

Ce texte débute par la mention du consulat, dignité mise en tête de la série des honneurs,

62 J. Firz, Legali leyionum Pannoniae superioris, dans Acla Antiqua, IX, 1961, 201; Legati Augusti propraelore Pannonie inferioris, ibid., XI, 1963, 268269 . 
placée en dehors de l'ordre chronologique, procédé très fréquent. Puis on retrouve dans l'ordre direct, les fonctions de la carrière sénatoriale du personnage qui débute par la préfecture. On passe ensuitc aux titres de commandant de légion en Pannonie supérieure et de gouverneur de la Pannonie inférieure ${ }^{63}$, alors gardée par une seule légion, la II AdiuIrix, fonctions l'une et l'autre données à d'anciens préteurs. Ces derniers doivent par conséquent précéder l'élévation de Iallius Bassus au consulat. On en ignore la date. Elle ne peut se situer qu'entre la rédaction du texte d'Aquincum, 156-158, d'après J. Szilágyi, et la curatelle des travaux publics qu'il exerce à Rome, en décembre 161, à l'avènement de Marc-Aurèle et de Verus ${ }^{64}$. On peut en déduire qu'il avait été revêtu du titre de consul dans l'une des trois dernières années du règne d'Antonin le Pieux.

Après cela le texte ne mentionne plus dans l'énumération que des fonctions d'anciens consuls. Celle de gouverneur de Mésie inférieure oì stationnaient deux légions : la I Ilalica et la $V$ Macedonica. C'est dans ce poste que Iallius Bassus a été comes de Vérus ${ }^{65}$ dans l'expédition contre les Parthes ; son successeur en Mésie Servillius Fabianus est mentionné avant la fin de 162. L'expédition contre les Parthes se termina en 165 et Vérus mourut au cours de l'hiver 169 ; c'est entre ces deux dates que doit prendre place le gouvernement de Pannonie supérieure où étaient cantonnées trois légions précédemment citées : la $I$ Adiutrix, la X Gemina et la XIIII Gemina. C'est

63 On a découvert ces dernières décennies à Aquincum cn Pannonie inférieure de nouvelles inscriptions, l'une provenant du palais du gouverneur mentionne Iallus Bassus: I.O.M. I et Laribus mililaribus Mrc / Iallius Bassus / ley auy / pr. pr., J. S\%ILAliY1, Les inscriplions d'Aquincum découvertes entre 19;1 et 19:3.3, dans Budapest Régiségei, XV1, 1955, p. 387, 426, d'où $A n$. Ep., 1962, no 117. Je tiens à remercier ici, M. H.-G. Pflavm et M1le C. Bémont qui m'ont aide dans les recherches, en particulier pour les textes récemment découverts en Europe centrale et orientale.

64 Kabı.上c, Real Encyclopädie IX (1), 1916, 625; A. DE Grassi, 1 Fasti consolari dell Jmperio Romano, Rome 1952, p. 45.

65 Marc Aurele n'a pas pris part personnellement a l'expédition contre les Parthes, la forme augustorum est donc abusive.

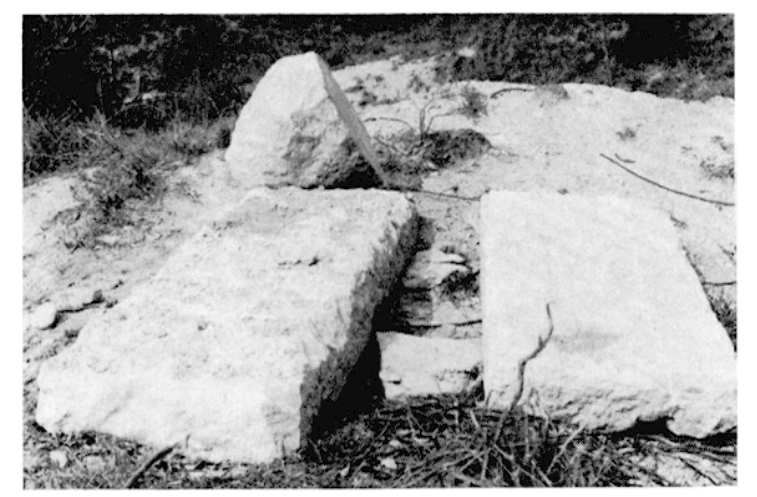

20 De gros blocs en calcaire, soigneusement taillés, gisent épars, sur les ruines du monument du mas Gradet.

par cette dernière fonction qui suit parfaitement la hiérarchie dans l'importance des provinces, que se termine la carrière politique de Iallius Bassus sur l'inscription de Rosières qui peut se restituer ainsi :

M(arco) Iallio M(arci) f(ilio) Vollinia Basso F'abio Valeriano co(n)s(uli) praetori leg(ato) leg(ionis) XIIII Geminae Marl(iae) Vict(ricis) leg(alo) aug(usti) pr(o)pr(aetore) / provinc(iae) Pannoniae inferioris curatori operum jublicorum leg(alo) augg pr(o)pr(aetore) provinciae / Mysiae inferior (is) comili augustorum Parlhicae exped(itionis) leg(ato) augg pr(o)pr(aetore) provinc(iae) Pannoniae superioris

On peut se rendre compte dans cette restitution que la partie gauche de la première ligne contient trois lettres de moins que la troisième ligne, pourtant de même longueur. Cela provient du fait que les noms, au début de l'inscription, étaient séparés par des points ou de plus grands espaces. Cette particularité est visible dans le manuscrit Calvet.

Le champ épigraphique avait environ $5 \mathrm{~m}$ de longueur, il était encadré en haut et en bas par une moulure de $0,17 \mathrm{~m}$ de large. On peut penser qu'elle se poursuivait sur les còtés, à droite et a gauche. Comme elle ne figure, ni sur la pierre complète dessinée par Galvet, ni sur celle qui nous est parvenue, il est probable qu'à l'origine, la partie verticale de la moulure ail été placée sur deux pilastres enserrant le linteau. Dans ce cas le monument construit au mas Gradet, en grand appareil, comme en témoignent les éléments encore en place (fig. 20), aurait eu près de $6 \mathrm{~m}$ de large. 
14. Bourg-Saint-Andéol. Le relief rupestre représentant Nithra tauroctone, entre les deux résurgences de la Tourne et du Grand Goul, a fait l'objet de nombreuses études ${ }^{66}$. Le bas-relief a été taillé dans le rocher naturel, un calcaire du crétacé inférieur, très dur, truffé de fossiles, qui souvent se présentent par tranche sous la forme d'un léger relief. Pour ménager le plan vertical, le sculpteur avait préalablement creusé une niche dont la profondeur s'amenuise vers le haut, ce qui a dégagé à la base une banquette fruste et irrégulière de 0,25 à $0,30 \mathrm{~m}$ de largeur. L'inscription occupe l'angle inférieur droit du bas-relief, elle se trouve aujourd'hui à $2,50 \mathrm{~m}$ au-dessus du sol. Ce dernier a été abaissé récemment pour aménager un terre-plein entre le ruisseau et le rocher, ces terrassements ont effacé toutes traces de construction.

L'inscription a èté martelée certainement a haute époque. Actuellement, malgré un petit auvent protecteur, le calcaire continue à ètre lessivé par les eaux de pluie chargée de dioxyde de carbone et la lecture devient d'année en année plus difficile. Le texte sur trois lignes est enfermé dans un cartouche mouluré à queue d'aronde, l. totale : $0,98 \mathrm{~m}$, h. : $0,35 \mathrm{~m}$ (champ épigraphique $0,70 / 0,26 \mathrm{~m}$ ), h. des lettres : $0.045 \mathrm{~m}$.

Pour tenter une nouvelle lecture ${ }^{67}$ nous avons branché, à un transformateur voisin, un câble électrique qui a permis l'utilisation de plusieurs projecteurs de théâtre de 1000 watts. Un échafaudage léger fut monté devant l'inscription pour permettre de photographier de face avec un certain recul ${ }^{68}$.

66 F. CcmoNt, Textes el monuments figurés relatifs aux mystères de Milhra, II, p. 401, no 279 ; Corpus Inscriptionum el Monumentorum Religionis Mithriacae, I, p. 309, no 895 .

67 CIL XII, 2706, F. CuмoNт, op. cit., II, p. 164, $\mathrm{I1}^{\circ}$ 501; Corpus Inscriptionum et Monumentorum Religionis Milhriacae, p. 309, no 897 ; VIviENne Walters, The Cull of Mithras in the Roman Provinces of Gaul, dans la série Éludes préliminaires anx religions orientales dans l'Empire Romain, 41, Leiden, 1974.

68 Lne centaine de clichés ont été pris de tout ou partie de l'inscription en faisant, varier les éclairages ou en superposant deux prises de vue sur la même photo avec des éclairages differents. Pour une série de clichés, le champ épigraphique a été recouvert
La pierre souillée par des traits de crayon ou de craie avait été préalablement lavée. Gràce au puissant éclairage frisant on a pu faire plusieurs constatations. Le lapicide a eu de grosses difficultés pour graver ce texte. La pierre s'écaillant facilement, il a fortement marqué les extrémités de chacune des lettres et cette incision, plus profonde, est restée apparente même quand le corps de la lettre a disparu. Pour les parties courbes, il a travaillé par percussion, ici encore la pointe de l'outil a laissé une légère trace encore visible. Dès l'origine les tracés n'étaient certainement pas réguliers, on peut penser que les défauts de la gravure furent corrigés à la peinture. Ces observations ont été faites aussi bien sur le rocher que sur les clichés ${ }^{69}$ oì ces différentes traces sont particulièrement mises en évidence.

A la première ligne il a été possible de lire sans difficulté : NVM . IIIRAE . . V .. La partie centrale fait immédiatement penser au mot Mithrae : NV.M[ini MILRAE... ou NUM[(ini) AVG M]IHRAE..

Cette hypothèse, souvent adoptée dans le passé, conduit à une impasse, de plus elle est, fausse, car on ne peut placer qu'une seule lettre avant le $r$, si l'on développe Numini. Cette lettre est parfaitement reconnaissable sur les clichés, il s'agit d'un $p$. Le deuxième mot de la première ligne commencerait donc par prae... Sur les clichés on reconnaît ensuite se puis vient le $u$ très visible sur la pierre. En fait, il ne s'agit pas d'un " mais d'un $n$ ouvert vers le haut dont la branche de gauche est très effacée. Il est suivi d'une haste et d'un $s$, les dernières lettres du mot sont moins hautes, plus comprimées et se terminent dans la moulure, comme pour la troisième ligne.

d'un enduit à l'eau blanc, sur une ipaisseur micrométrique, ce qui a largement alténue l'effet des différences de teintes de la roche naturelle el des incrustations de lichens. L'organisation matérielle : échafaudage et ligne électrique ont été réalisés grace au concours de la municipalité de Bourg-Saint-Andéol el de l'EDF, yue je tiens à remercier ici.

69 Ies observations sur les cliches onl ite faites le plus souvent sur le négatif, ètudiè à la loupe binoculaire, grossissement 10, double eclairage, transparence et réflexion. 
On reconnaît après les $s$, un $m$ et un $o$. On aurait donc, au commencement de ce texte : Numini praesentus(si)mo $o^{70}$. La suite, occupant loute la deuxième ligne, est bien connue, sa lecture est assurée, il s'agit de l'accusatif deum invictum, complément d'objet direct du fecit qu'on retrouve plus loin. La troisième et dernière ligne comporte au centre une importante lacune. On lit très bien à gauche $T$. IVR... et à droite ...N $D(e) S(u a)$ $P$ (ecunia) $F$ (ecit), il reste entre les deux un espace pouvant contenir 7 à 8 lettres pour lequel nous avons au milieu un élément de $m$. Sur les clichés on retrouve avant le $m$, us et avant le $n$ une courbe appartenant à un $o$. Une petite difficulté existe au début de la ligne, après le $T$ dı prénom Titus, une hedera et une haste parfaitement verticale qui ménage un espace, un peu grand, avec la lettre suivante un $u$. Sur les clichés on trouve au bas de la ligne une petite trace qui a quelquefois fait, lire Aur(elius). En fait, la partie visible de la première lettre est trop verticale pour correspondre au jambage gauche d'un $a$. On peut se trouver en présence de in, le $\|$ visible, très ouvert, pourrait comme à la première ligne, être un élément de $n$, ce qui nous donnerait pour le début du nomen INR.VS. Une solution plus acceptable est de raccorder le petit élément visible entre les deux lettres avec la haste initiale et de le transformer en $l$, nous aurions ici le nomen $L V R[i] V S$, attesté en Gaule ${ }^{71}$. Pour le cognomen nous avons la première lettre $m$ et les dernières on avec une lacune de deux lettres. Nous proposons MYRON, attesté en Narbonnaise et à Lyon ${ }^{72}$. Les dernières lettres du texte, bien visibles, ont déjà été interprétées. Nous proposons pour la restitution totale :

NVMINI PRAESENTISSIMO / DEV.U INVICTVM I T(ilus) LVRIIS MYRON D(e) S(ua) P(ecunia) F(ecil)

\section{André Blanc:}

70 La formule Numini praesentissimo ast conmur dans le culte de Mithra, CIL XIV, 3567.

71 CIL XIII, 5008; CIL XII, 5678 ${ }^{11}, 56 \times 55^{25}$.

72 CIL XII, 1595, 1637, 1898, 3645, 4127, 5058; CIL XIII, 1734, 1736, 2288.
III. Inscriptions de LA Cité des Voconces (DRômE)

1. Petit autel réemployé dans le pied-droit d'une cheminée à Pauliane (commune de Luc-en-Diois), dans une dépendance de la ferme de .Ime Chalfois, aujourd'hui de II. Prévosteau. Iarg. : $0,19 \mathrm{~m}$; h. : $0,47 \mathrm{~m}$; ép. : $0,15 \mathrm{~m}$. Noulures de la base el du couronnement bûchées sur les faces principale et gauche, reconnaissables à droite (fig. 21 ).

\section{QVINTI \\ O SOLI.F \\ M V.S.L..II}

Lettres de $0.04 \mathrm{~m}$ (1. 1 et 2 ) et 0,032 (1. 3). $T$ s'élevant au-dessus des lettres voisines. Au-dessous du lexte ont été ajoutées une date et une croix : $17+99$.

$V u$ en 1969; en place en 1973. Signalé par un manuscrit de la collection Charles Béranger, à Die ${ }^{1}$.

Quinti/o Soli f(ilius) / M(ercurio) u(olum) s(oluit) l(ibens) m(erilo) /.

Le cognomen Quinlio est attesté dans la région de Narbonne, à Lyon et à Reims ${ }^{2}$. Soli parait ici, avec une autre orthographe ${ }^{3}$, le génitif de Sollius, gentilice connu dans les Trois Gaules comme en Narbonnaise et à Die même, et qui pourrait être d'origine celtique ${ }^{4}$.

1 Mémoire des Monumenls de science et d'art qui se trouvenl à Die, p. 13. Les douze premieres pages du manuscrit sont de L.-.J. Iagier de Vaugelas el datent de 1794 ; le reste est d'une autre main (sans doute du D" J.-D. Long).

2 CIL XII, 4265, 4679, 5167 ; XIII, 1817, 3313.

3 Cf. CII, XIII, 6972 : P. Solius P. F. Suauis.

4 CIL XII, 1667 (Die, 2181, 2252, 2316, 2461, $3952 ;$ X111, 1946, 2274, 5573, 6739, 6972, 11539, 119.46. (if. A. HoLn:R, Allcellischer Sprachschatz, Leiprig, 1896-1920, s. $v$. 


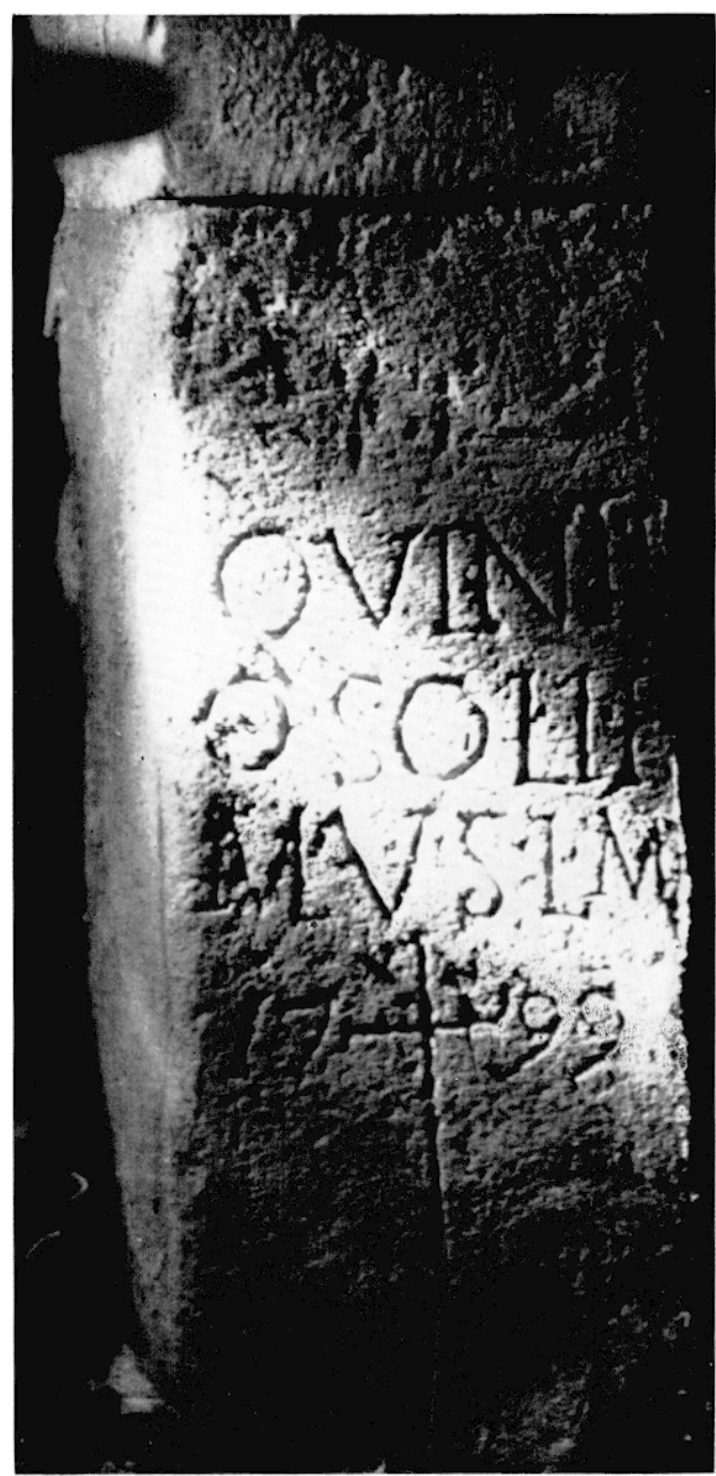

21 Paulianc. Autel à Mercure (no 1).

Ici naturellement il s'agit d'un cognomen ou nom unique.

Il ne fait guère de doute que l'abréviation $M$, à la troisième ligne. ne doive sc développer en.$M$ (ercurio $^{5}$. Pauliane avait livré en 1794 une dédicace à ce dieu ${ }^{6}$ et nous avons publié un autel octogonal existant au mème endroit.

5 Cf. $C I L$ XII, 1086.

6 Ibid., 1570 : Mercurio / Nouellus ! Jouincati (filius) i n(otum) s(oluit) l(ibens) m(erito) $/$ (On observe là le même passage de l'onomastique celtique à l'onomastique romaine que sur notre petit autel. sur la surface supérieure duquel est sculpté un serpent lové et dont le dé conserve une dédicace à Mercure? . I a forme du monument et le texte de la dédicace ne nous ont d'ailleurs pas paru présenter toutes les garanties de l'authenticité et nous nous demandons s'il s'agit d'une cuvre antique ou d'un faux qu'un amateur local du $x^{\prime} x^{e}$ s. aurait commis à partir des deux dédicaces authentiques de Vovellus et de Ouintio.

Quoi qu'il en soit, Pauliane paraît constituer le centre d'un grand domaine et avoir possédé un sanctuaire rural de Mercure. La présence de plusieurs ex-voto explique d'ailleurs que le nom du dieu ait été réduit sur notre petit autel au sigle $\boldsymbol{M}$.

Les deux - ou Lrois - ex-voto de Pauliane restent les seuls témoignages épigraphiques que nous ayons sur les cultes dans la région de Luc $^{8}$, si nous exceptons un petit autel à une déesse augruste (Andarla vraisemblablement) ${ }^{9}$.

Les lettres de notre dédicace, assez peu régulières, gardent trace du mouvement de la main avec les barres du $T$ et du $F$ légèrement obliques. On a vu que le $T$ est plus haut que les lettres voisines. I a queue du O. assez Iongue, ne rappelle pas celles, bien plus courtes, que nous trouvons dans certaincs épitaphes oì le nom du défunt est au datif ${ }^{10}$; en revanche, elle ne revient pas en s'infléchissant vers la ligne, comme cela se voit sur des textes de bonne époque ${ }^{11}$.

Ce sont là des indices assez minces. Nous avons cependant l'impression qu'il s'agit d'un texte du Haut-Empire. Rappelons que la dédicace faite par Novellus, avec sa paléo-

7 Année spigraphique (en abrégé : $A E$ ), 1969-1970, $357=$ Gillial, XXVII, 1969, p. 214-215.

8 Nous entendons par région de Luc ce qui devait en constituer le pagus, qui comprenait vraisemblablement la combe de Die au sud du Bez et devait s'étendre au bassin supérieur de la Dròme, peut-être jusqu'aux sources et au col de Cabre (Gaura mons).

9 E. Espéraxileu, Inscriptions lalines de la (iaule Narbonnaise, Paris, 1929 (en abrégé : ILGN. 230 (Luc:.

10 ClL XiJ, 1630 (Luc : Gallia, loc. cil., p. 208; IL (i.N, 243 (Die.

$11 I L G . V, 247$ et, plus loin ici, no 9. 


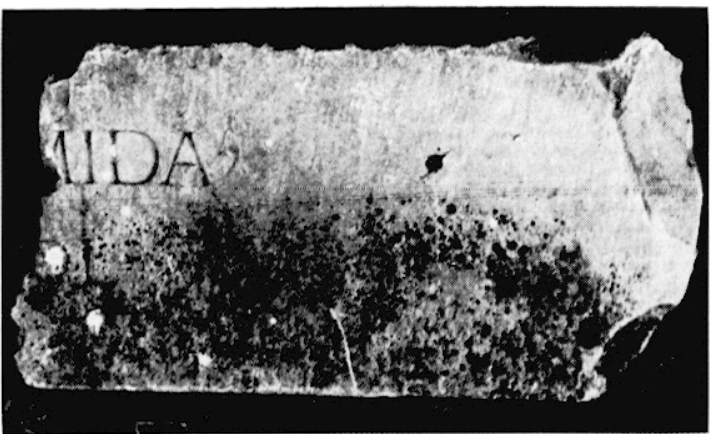

22 Pauliane. Fragment de siège (no 2).

graphie, et notamment la forme de ses $R$, paraît remonter à cette même période.

2. Plaque de calcaire dur trouvée il y a plus d'une dizaine d'années à la ferme de Pauliane, chez $\mathrm{M}^{\mathrm{me}}$ Chaffois. Larg. : $0,73 \mathrm{~m}$; h. : $0,36 \mathrm{~m}$; ép. : $0,09 \mathrm{~m}$. La plaque est complète en haut et en bas, peut-être à droite, mutilée à gauche ; l'inscription complète à droite. Isa face qui porte l'inscription se présente légèrement creusée dans le sens de la longueur, d'une profondeur d'environ $0,01 \mathrm{~m}$. Cette face garde la trace des coups donnés par l'instrument du tailleur de pierre, formant ainsi une sorte de piquetage. La tranche d'en bas est très lisse, celle d'en haut moins soignée; le dos de la pierre simplement dégrossi ( fig. 22).

\section{MIDA. \\ $\mathrm{OI}$}

L. 1 : bonnes leltres de $0,05 \overline{5} \mathrm{~m} ; M$ mutilé ; hedera après $A$.

L. 2 : lettres de $0,045 \mathrm{~m} ; O$ mutilé.

Vu en 1969 ; en place en 1973.

... Numida. / ... clol(oniae?) ou inc?ol(a)? 1 .

Nous songeons au cognomen Numida, bien connu dans le monde romain et attesté en Narbonnaise ${ }^{12}$.

La forme de la pierre fait penser à une banquette et nous avons peut-ĉtre ici, bien plutòt qu'un siège de spectacle, les restes de la partie rectiligne d'une exèdre, funéraire ou non.

Nous ne pouvons nous empêcher de rappro-

12 CIL XII, 1830 et 2629. cher ce fragment d'un autre texte de Luc, inscrit sur une colonne et dont la partie droite subsiste seule aujourd'hui ${ }^{13}$ :

$$
\begin{array}{cl}
\text { V.IVI } & \multicolumn{1}{c}{\text { OL }} \\
\text { ANVS } & \text { MED } \\
\text { ACO } & \text { CINEN }
\end{array}
$$

Un manuscrit du $D^{r}$ J.-D. Long, de la collection Charles Béranger, à Die ${ }^{14}$, en donne la lecture suivante :

$\begin{array}{cc}\text { V IVL } & \text { VOL } \\ \text { INVS } & \text { IED } \\ \text { ACO } & \text { GINEN } \\ S & \end{array}$

Ce qui subsiste de la colonne présente, comme la banquette, des traces de piquetage dues au ciseau; les lettres paraissent assez archaïques ( $O$ très rond, $N$ et $E$ élevés).

Herzog ${ }^{15}$, critiqué par $C I L$, voyait dans cette colonne l'épitaphe d'un médecin : V(iuus) Iul(ius) ...ol/anus med(icus) / [Vo]co[nt(iorum) cine $<r>$ (arium) [s(ibi) f(ecil)] $/$. Nous proposerions, à titre d'hypothèse, l'essai de restitution suivant: V(iuos) Iulius Vol/anus $[N u]$ med/a co[l(onia) $] \ldots$ ginen $/ s(i) /$.

Le $V$ initial se rencontre sur des épitaphes des Alpes Cottiennes et, surtout, de Narbonne ${ }^{\mathbf{1 6}}$. Volanus, si le $V$ a bien existé, peut correspondre à une prononciation de Bolanus, cognomen connu. L'orthographe Numeda pour Numida serait plus difficile à expliquer : un trait surmontant la haste du I aurait fait prendre, peut-être, cette lettre pour un $E$.

Il pourrait s'agir d'un personnage originaire

13 Ibid., 1622 ; J. SAltes, Carte archéologique de la Gaule romaine, Carle el texte du déparlement de la Jrôme, laris, 1957 (en abrégé : FOR), 69,7; 76, 133 bis (donné par erreur comme trouvè à Die); Appendice épigraphique, 32 .

14 Nolice sur les Vocontii on Vocuntii, peuple de la Gaule Narbonnaise: Inscriptions de Die, avec 76 inscriptions estampées el 61 dessins ou calques, envoyée à l'Académie des Inscriplions pour le prix à décerner en 1840 sur les Antiquilés de la France (cahier de 28 p.;, p. 18 .

15 Galliae Narbonensis provinciae Romanae hisloria, descriptio, instilutorum expositio, L.eipzig, 1864, p. 101, n. 476.

16 CII. XII, 89, 95, 4286, plus une cinquantaine d'exemples a Narbonne, qui paraissent remonter all $1^{\text {er }} \mathrm{s}$. 


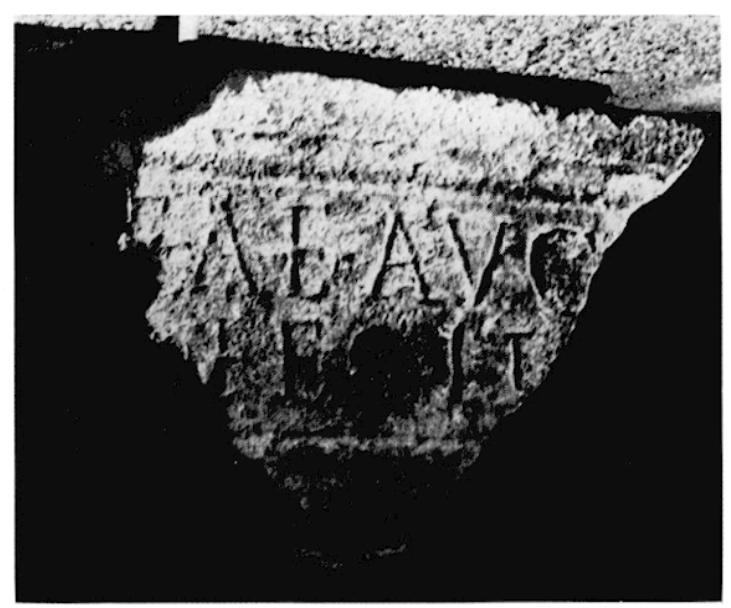

23 Barnave. Fragment de l'épitaphe d'un pontife $\left(n^{\circ} 3\right.$ :.

d'une colonie; dans ce cas, on serait tenté de restituer co[l(onia) Cartha]gin $<i>e n / s(i)^{17}$, sans oublier d'ailleurs que Carlhaginiensis. ferait tout aussi bien allusion à Carthago nova qu'à Carthage, l'une et l'autre colonies. L'origine africaine du défunt expliquerait alors facilement le second cognomen ou l'indication d'origine Numida, bien que ce surmon reste connu dans la région de Sagonte ${ }^{18}$.

Moins vraisemblablement, l'on pourrait se demander si colonia, ici comme en CIL XI, 1147, ne désignerait pas une portion de sallus, peut-être impérial, sur lequel se sont établis des coloni. Naturellement l'existence d'une colonia ... ginensis à Pauliane n'est pas confirmée par d'autres documents.

La colonne, CIL XII, 1622, peut avoir été élevée pour porter une urne cinéraire. Se pourrait-il qu'elle ait surmonté l'exèdre dont il reste un fragment à Pauliane? La colonne semble présenter des mots mal coupés et même mal orthographiés, ainsi qu'une paléographie assez archaïque ${ }^{19}$; cela fait contraste avec la beauté des lettres de l'exèdre. S'il est loin d'être évident que ces vestiges aient appartenu

17 Pour l'orthographe Carthagin<i>ensis, ef. CIL II, 3602 : XIII, 2000 et 8269 ; pour la formule, cf. $A E, 1966,191: C$ (aio) L(icinio?) Vilico c(oloniae) $V$ (ictricis), et $614: F a(n i$ ?) Fo[rt(unati)] col(onia) $H[$ adr (umeto) $]$.

18 CIL II, 3845, 3850, 4033.

19 Et un chapiteau, très mutilé, s'amorçant par un cavet sur le fùt de la colonne. au même ensemble, la taille de la pierre reste semblable, on l'a vu, et la colonne, comme la banquette, doivent remonter à la même époque, que le $V$ initial fait assimiler au ${ }^{\mathrm{er}} \mathrm{s}$.

3. Fragment découvert au printemps 1969 dans l'écurie de M. Lagarde, dans la GrandRue du village de Barnave (canton de Lucen-Diois) et donné par le propriétaire au musée de Die. Larg. : $0,55 \mathrm{~m}$; h. : $0,36 \mathrm{~m}$; ép. : $0,21 \mathrm{~m}$. Galcaire blanc. Complet en haut et en bas (moulures), incomplet à gauche et à droite. Ia moulure fait une sorte de bourrelet ou ressaut supplémentaire à l'endroit où elle rejoint le champ épigraphique (fig. 2:3).

\section{EAE.AVG .FEGIT}

Bonnes lettres de $0,07 \mathrm{~m}$ (1. 1) et 0,061 (1. 2). L. 1 : premier et dernière lettres mutilées.

Il s'agit là d'un troisième fragment de l'épitaphe $C I L$ XII, 1589, dont deux parties avaient été trouvées dans le cimetière de Barnave, la première en novembre 1842 (actuellement dans la collection Vallentin du Cheylard, à Montélimar), la seconde en 1845 (fragment perdu) ${ }^{20}$. Un estampage du premier texte et un dessin du second, dus au docteur J.-D. Long'21, confirment, tant par les dimensions que par la disposition des lignes, que nous nous trouvons bien devant un troisième fragment de la même épitaphe, qui se restitue ainsi :

... Voc(ontiorum) pọnlific $i$ D eae Aug(uslae) [Voc(ontiorum?)] / . . coniugi? optimo el sibi $\underline{u}[$ iula $]$ fecil /.

Ce texte ne manque pas d'intérêt par suite de la mention sur la même pierre d'une fonction commune aux Voconces - [decu]r(ioni) ou, plus vraisemblablement, [praeto $] \cdot(i)$ - et d'une fonction religieuse propre à Die. Sans vouloir entrer dans le détail, que l'un d'entre nous pense exposer ailleurs, nous nous conten-

20 CIL XII, 1589 et 1589 suppl. : J.-P. Revel.t.AT, Quelques Inscriptions romaines vues dans les départements de la Dròme et de l'Ardèche, dans Bulletin épigraphique de la Gaule, VI, 1886, p. 74-76 et 137.

21 Musée de Die, fonds Charles Béranger. 
terons de rapprocher ce texte d'une épitaphe d'Entrechaux, où le défunt a exercé les fonctions d'édile, de préfet, de préteur, de flamine du divin Auguste et de pontife à Die ${ }^{22}$. On a l'impression que ces deux textes se rapportent à une même époque, où la cité des Voconces gardait peut-ètre encore une administration commune, mais où I uc avait déjà cédé son rang de capitale religieuse à Die et où cette dernière ville jouissait de la présence de certains prêtres, pontifes et, sans doute, flamines ${ }^{23}$.

L'épitaphe d'Entrechaux, au datif, remonte au I er s.; celle du Monestier d'Allemont, avec Dis Manib(us), se situe entre 70 et 100 ; celle de Barnave, inscrite sur un bandeau d'au moins 1,40 $\mathrm{m}$ de long et possédant une doucine à ressaut, paraît remonter à la scconde moitié de ce siècle ou au tout début du ${ }_{11}^{\mathrm{e}}$.

4. Fragment d'inscription inédit et perdu, connu par un estampage fait par le $D^{r}$ J.-D. Long ${ }^{24}$ et accompagné de la note suivante : Celle inscription, presque enlièrement effacée, se lrouve encore parmi les ruines du château d'Aix, à une lieue au-dessus de Die (Aix-enDiois, canton de Die). Larg. : $0,49 \mathrm{~m} ; \mathrm{h}$. : $0,30 \mathrm{~m}$ (dimensions approximatives). Moulure en haut, semble-t-il ; incomplet en bas et ì droite.

\section{MAT'RNI. MIRI \\ F. AAT'RNIVS IAI RIANVS. .}

Texte difficile à lire. Lettres de $0,04 \mathrm{~m}$.

L. 1 et 2 : dernière lettre réduite à un fragment de haste.

L. $2: F$ ou $T$.

$$
\begin{aligned}
& {[D(\text { is) (.M)anibus)] / Malerni . Tarị(i) | }} \\
& \text { f(ilii) Maternius Va! [e]/rianus... }
\end{aligned}
$$

22 CIL XI1, $1371: Q($ uinlo) Po[mpeio ... fil(io)]! Volịt(inia)] ... / aedil(i) [Vocont(iorum?)] / praef(ecto) Bo[don?] / fior (um) pr (aetori) V[oconl (iorum?)] ! flamini d[iui Aug(usli)] / pontif(ici) $D[$ eae Aug(uslae)] /, etc.

23 Ibid., 1529, Monestier d'Allemont : ...praef(ecti) / pagi Epoli Ram(inis) Aug(usli) et / muner(is) publici curat(oris) I ad Deam Aug(ustam) Voc(ontiorum) /, etc. et 1585, Die : ...flamini diui Aug(usti) | ilem famini el curaltori muneris gladilatori(i) Villiani, etc.

24 Musée de Die, même fonds.

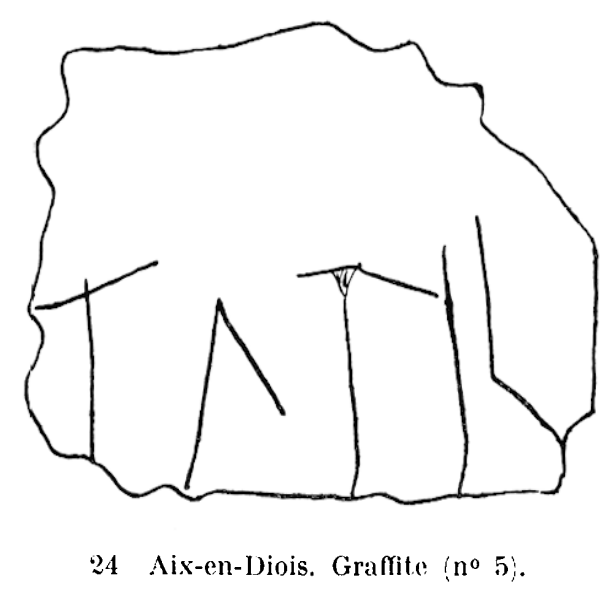

Peut-être Mari, Mari[ni], Mart $\left[\right.$ ini $^{25}$ ou un cognomen voisin. Marius est connu comme cognomen à Valence ${ }^{26}$, Valerianus est très commun $^{27}$. Il semblerait que l'auteur de l'épitaphe ait tiré son gentilice du cognomen du défunt, peut-être son père, pour donner à son nom une allure plus conforme à l'onomastique des hommes libres ${ }^{28}$.

Malernius n'était pas attesté à Die, à la différence de Malernus $^{29}$. On remarquera que dans deux ex-voto locaux mentionnant ce dernier cognomen on trouve les ligatures 3 ou $\Lambda A^{30}$. Nous préférons ne rien conclure, quant à la date, de la présence de cinq ligatures dans notre texte.

I.es ruines du château féodal d'Aix-en-Diois ont livré plusieurs fragments épigraphiques ${ }^{31}$, qui peuvent provenir de Die, les pierres de la cathédrale ayant servi vers 1594 aux répa-

25 (Cf. a l)ie, pour Marius, CIL, XII, 1641 et 1663 (= FOR, App. épigr., 25); pour Marinus, 1641 ; pour Martinus, 1672.

26 CIL XII, $1567:$ L. Dagidius Marius.

27 A I)ie, ibid., 1592, 1609, 1670, 1726 (Crest).

28 A. Allatir el P. Dissard, Musée de Lyon, Inscriptions antiques, Lyon, 1888-1893, V, p. 142, donnent une liste sommaire des gentilices tirés des cognomina: ils citent notamment Malernius (III, p. 347 !

29 ILGN, 242 (Malerna); HOR, App. épigr., $38 ; A E, 1965,169 ; 1969-1970,347 . \Lambda$ Lyon on connaît le Voconce L. Maternius Maturus (CIL XIII, 2017). $30 \mathrm{AL}$, loc. cit.

31 CIL XII, 1661 ; FOR, App. épigr., $60 \mathrm{ol,} \mathrm{ici,}$ no 7 . 
rations de l'édifice ${ }^{32}$, mais qui peuvent aussi avoir une origine locale, une villa ou petit sanctuaire ayant été repéré à $500 \mathrm{~m}$ environ du château ${ }^{33}$.

5. Graffite sur enduit trouvé en 1969 dans l'entassement de matériaux qui remplissait le grand hypocauste d'un établissement fouillé au quartier de l'Oche, à Aix-en-Diois. Larg. de la partie enduite : $0,06 \mathrm{~m}$; h. : $0,05 \mathrm{~m}$; ép. : $0,04 \mathrm{~m}$. Le graffite, trouvé à $0,40 \mathrm{~m}$ du fond, a pu tomber du mur ouest de la salle. Le fragment comprend, de l'extérieur à l'intérieur, un enduit rouge sur mince couche de stuc, une couche de mortier gris, puis de mortier rose. Texte incomplet, au moins à droite. Au musée de Die (fig. 24).

\section{TATILI}

Lettres de $0,025 \mathrm{~m}$, gravées à la pointe. $A$ sans barre horizontale, $L$ à barre inférieure oblique, $I$ final indiqué par la cassure. Lettres légèrement mutilées à leur base.

Signalé dans le rapport de fouilles de 1969 adressé à la Direction des Antiquités historiques de la région Rhône-Alpes.

Il faut vraisemblablement restituer $[S]$ tali I $^{-}$ !i [us] ou, peut être, T(ilus) At!l! i[ [us]. Le premier nom est connu à Sainte-Croix, près de $\mathrm{Die}^{34}$, l'autre à Die même ${ }^{35}$.

Il n'y a pas grand-chose à dire de la paléographie de ce graffite. Une tasse trouvée dans les matériaux du grand hypocauste parait remonter au $\operatorname{III}^{\mathrm{e}}$ ou IV $^{\mathrm{e}}$ s., mais le site a livré des fragments de céramiques de la fin du ler s. $^{36}$.

6. Des hypocaustes du même établissement proviennent trois fragments de legulae ocre portant sur leur tranche un graffite gravé avant la cuisson; déposés au musée de Die.

a) Mutilé de tout côté. L. du fragment :

32 J. Chevalier, L'Abbaye Notre-Dame de Valcroissant, de l'ordre de Citeaux, au diocèse de Die, Valence, 1898, p. 49, n. 2.

33 Cf. ici nos 5 et 6 .

34 CIL XII, 1574 : Statilius Carpophorus.

35 Ibid., 1604: C. Atilius Decuminus et Atilia Stasime; $1605:$ L. Alilius Dionysius.

36 Gallia, loc. cit., p. 218.
$0,15 \mathrm{~m}$; larg. : $0,13 \mathrm{~m}$; ép. : $0.028 \mathrm{~m}$. Entré au musée en 1972.

\section{V}

La lettre occupe toute la hauteur de la tranche. Les deux branches du $V$ ne se rejoignent pas en bas.

b) Mutilé de tout côté. L. : 0,054 m ; larg. : $0,08 \mathrm{~m}$; ép. : $0,032 \mathrm{~m}$. Trouvé en surface dans le grand hypocauste en 1966.

\section{IV}

$V$ de même type que précédemment. La tranche étant usée à gauche, il peut s'agir aussi bien de $V V$ que de $I V$.

c) L. : 0,09 m ; larg. : 0,13 m ; ép. : 0,028 m (avec le crochet : $0,056 \mathrm{~m}$ ). Trouvé en 1973 .

\section{I}

Deux autres graffites, numérotant sans doute les piles de legulae pour la cuisson ou le stockage, avaient déjà été trouvés dans les fouilles de l'Oche ${ }^{37}$. Nous avons supposé que les tegulae étaient empilées crochets en bas; sur le graffite $a$ ) encore, c'est dans cette position que le $V$ se lit à la tranche de la legula ${ }^{38}$.

Aux Brus, près de Beaufort-sur-Gervanne (canton de Crest-Nord), M. Jean-Noël Couriol avait signalé de pareilles marques artisanales ${ }^{39}$. Il est curieux de noter que les seuls chiffres rencontrés jusqu'ici dans le Diois sont $V$ et $I$. $V V$ a été lu aux Brus.

7. Fragment de calcaire dur réemployé en linteau de porte dans une construction en ruines appartenant à $M$. Georges Deschamps, au village d'Aix-en-Diois. Larg. : $0,26 \mathrm{~m}$; h. : $0,98 \mathrm{~m}$; ép. : $0,16 \mathrm{~m}$.

$$
\mathrm{S}
$$

Très belle et grande lettre, terminant un mot disparu, haute de $0,19 \mathrm{~m}$.

$\mathrm{Vu}$ en 1972 ; en place en 1973.

37 Ibid.

38 Le fragment ne présente plus de traces de crochets, mais des stries indiquent clairement la face inférieure de la tegula.

39 Ibid., p. 217. 


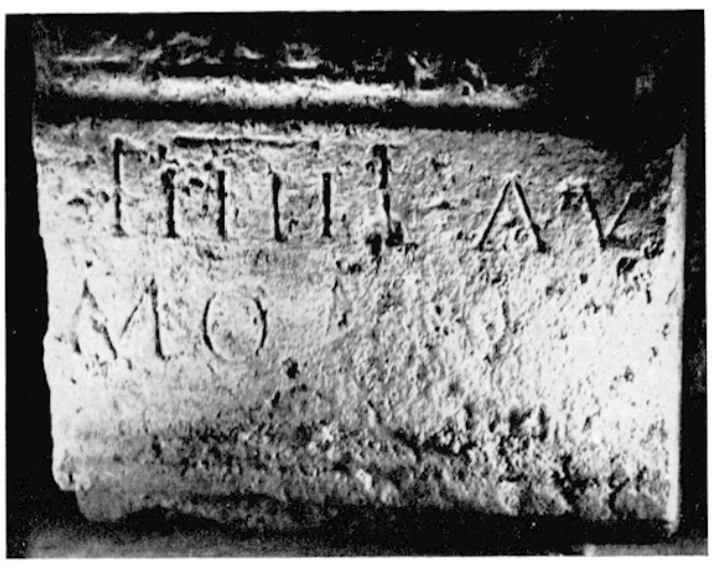

25 Die. Fragment de l'épitaphe d'un sévir $\left(n^{\circ} 8\right)$.

Les dimensions du $S$ et l'espace qui subsiste au-dessus font penser à un texte monumental.

8. Fragment d'entablement calcaire, retaillé et ayant servi de pied-droit dans un portail du Clos-Lambert, roule de Romeyer, à Die. L'inscription a été découverte le 27 novembre 1972. Larg. : $0.77 \mathrm{~m} ;$ h. : $0.53 \mathrm{~m}$; ép. : 0,53 m. Le texte, de deux lignes, incomplet à gauche et à droite, est contenu dans un cartouche mouluré (doucine sins ressaut). Un cavel (ou une moulure mutilée d'un type voisin; se voit à la base de la face écrite. Au musée de Die, donné par MII. Audra frères (fig. 25).

\section{- IIIIII $\cdot \mathrm{AV}$ IIO}

Lettres de $0,071 \mathrm{~m}$; hastes extrêmes de IIIIII $: 0,085 \mathrm{~m}$.

... sex (uirn) $A u[g($ uslali) $] \ldots / \ldots[\ldots i s-$ si]mo $/$.

IIIIII Aug(ustalis) constitue une abréviiltion assez fréquente pour ITIIII uir Aug(ustalis) ${ }^{40}$. Notre anonyme vient s'ajouter aux cinq sévirs augustaux que l'on connaissait déjà à $\mathrm{Die}^{41}$.

Le cavet qui se creuse au-dessous de l'inscription montre que ce texle était écrit sur un

40 CIL XII, 1370, 2237, 2247, 3198, 3270, $4377,4438$.

41 Ibid., 1580, 1581 (seuiri Auguslalis Dea Augusta Vocontiorum), 1582, 1583, 3290 (seuiri Augustalis corporali Dea Augusta Vocontiorum).
Jong bandeau servant d'entablement ${ }^{42}$. Ce genre d'épilaphes paraît remonter au $\mathrm{I}^{\mathrm{er}}$ ou à la première moitié du ${ }_{\mathrm{II}^{\mathrm{e}}} \mathrm{s.}^{43}$

9. Fragment d'entablement en beau calcaire dur, découvert le ler avril 1969 à Die, lors de la démolition d'une tour de l'enceinte du Bas-Empire, au pied de la montée menant à l'Évêché ; le bloc était à la base de la tour. Larg. : $1,21 \mathrm{ml}$; h. : $0,51 \mathrm{~m}$; ép. : $0,48 \mathrm{~m}$. L'inscription, incomplète à droite, est contenue dans un cartouche mouluré; au bas de la face principale, une doucine. Au musée de Die (fig. 26).

\section{SEX C COELIVS SIGERV QVINTILLAE}

Bonnes lettres de $0,068 \mathrm{~m}$.

\author{
Sex(lus) Coelius Sigeru[s? .../ Quintil- \\ lae .../.
}

Le gentilice romain Coelius est attesté dans la région ${ }^{44}$. La Narbonnaise a livré deux exemples du cognomen Sigerus ${ }^{45}$, d'origine grecque $^{46}$ : il pourrait peut-être s'agir ici d'un affranchi. Quintilla est altestée à Aix-enDiois ${ }^{47}$. On notera l'abondance des cognomina féminins en -illa à Die ${ }^{48}$, ce qui peut s'expliquer par la confusion avec un suffixe celtique ${ }^{49}$.

Lal seconde ligne, incomplète, devait sans

42 Cf. ibid., 1691 b; 1722 (=FOR, App. épigr., 63: et ici nos 9 et 13 , textes de deux lignes seulement, sauf le $\mathrm{n}^{\circ} 13$, qui ont une moulure en doucine au bas de la face principale.

43 H. DESAYE, Les Inscriptions funéraires des Voconces de Die, dans Rhodania, Congres de Valsles-Bains 1956 , p. 64.

44 A Die même CIL XII, 1563 (C. Coelius Hermagoras), 1610 (Coelia Marcella), 1613 (T. Coelius Asinlicus).

15 Ibid., 1191 et 5690,80 .

46 W. PAPE il G. Brossingn, Worterbuch der (iriechischen Eigennamen, nouvelle édition Graz,

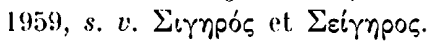

47 CIL XII, 1661.

48 Carilla (ibid., 1616, 1679), Decumilla (1569), Gralilla (1644; AE, 1961, 163 a), Maximilla (CIL XII, 1723, Aouste), Mercatilla (1663), Paternilla (1629), Quintilla (1661 et ici n"9), Secundilla (1562; ILGN, 236, Servalilla (CIL XII, 1664, Vrbicilla (1683), Verilla 1715, Eyzahut; 1717, Pont-de-Barret.

49 I. Karanto, The Lalin Cognomina, Helsinki, 1965, p. 127. 


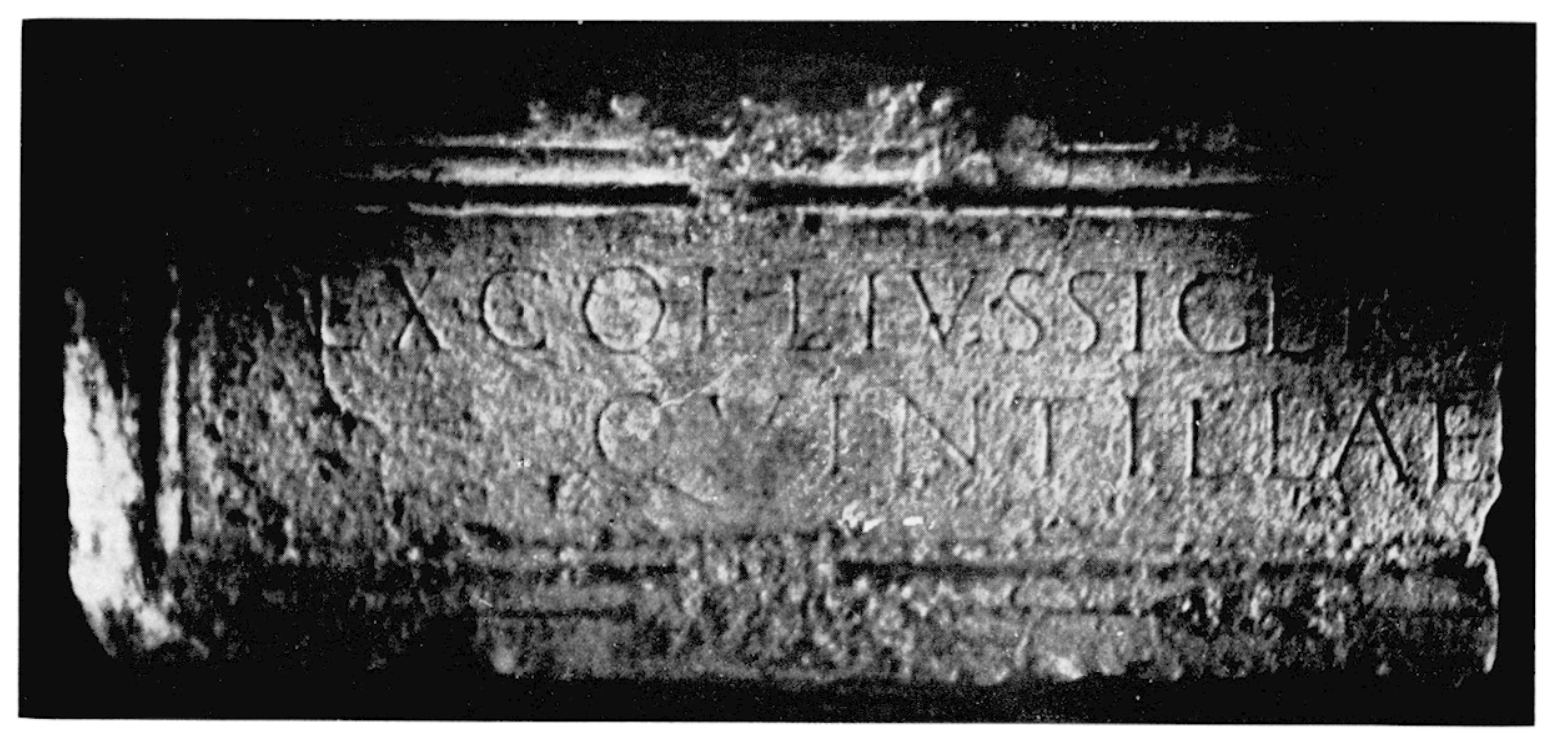

26 Die. Épitaphe de Quintilla (no 9 ;.

doute contenir, à la suite du nom de la défunte, son titre de parenté : filiae, uxori ou liberlae. Deux épitaphes de Die commencent par le nom du dédicant au nominatif, suivi du nom du défunt au datif : l'une pourrait être antérieure à la généralisation de la dédicace aux dieux Mânes ${ }^{50}$, l'autre est manifestement plus tardive $^{51}$. Ce qui confirmerait l'attribution de notre texte au i ${ }^{\text {er }}$ s., c'est le fait qu'il est gravé sur un entablement, comme les nos 8 et 13 ; que la moulure présente un ressaut supplémentaire $^{52}$; que les lettres sont belles, notamment le $Q$, dont la queue se développe largement avant de se recourber. Il y a là un faisceau de présomptions pour situer l'épitaphe de Quintilla avant les années 120-130.

10. Fragment de stèle en calcaire dur encastré dans le mur de la ferme de M. Chabuel, au quartier de Béconne, à Die. Larg. : 0,37 m ; h. : $0,53 \mathrm{~m}$. La pierre est incomplète à droite

50 CIL XII, 1623 (épitaphe sur deux lignes) : ...uilius Ianuarius fla... / ...minae uxori oplimae/. Le nominatif est de rigueur lorsqu'un vivant fait pour lui-même le tombeau : ibid., 1598, 1613, 1614.

51 Ibid., 1679: $D$ (is) M(anibus) / el securilali ! Q(uintus) Verrius Bassus uiuus sibi / rt Carillae filiae jecitl.

52 Gallia, XXII, 1964, p. 271.

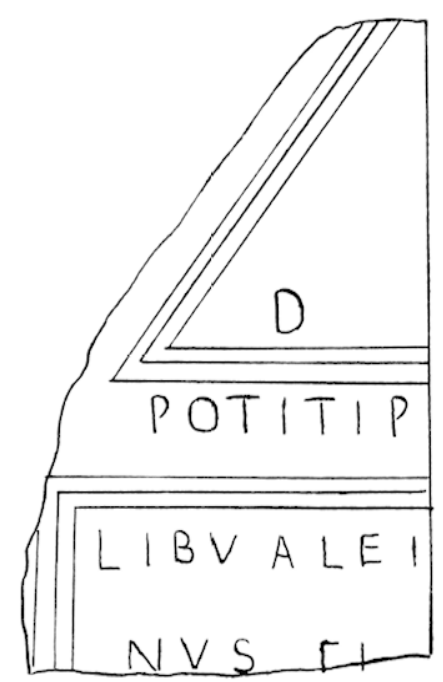

27 Die. Épitaphe de Polilus ( $\mathrm{n}^{\circ} 10$ ).

el en bas. La ligne 1 se trouve inscrite dans le fronton triangulairc mouluré, les lignes 3 et 4 dans un cartouche mouluré. Moulures en doucine sans ressaut (fig. 27).

$$
\begin{gathered}
\text { D } \\
\text { POTITI P } \\
\text { LIB VALEI } \\
\text { NVS F FI }
\end{gathered}
$$

Lettres de $0.04 \mathrm{~m}$ (l. 1) et $0,0: 38$ (1. 2 à 4$)$, correctes. 
L. 3 : dernière lettre réduite à une haste. L. 4:S, $F$ et $I$ mutilés en bas.

Vu en 1972 ; en place en 1973.

D(is) [M(anibus)] / Potili P... / lib(erli) Valer [ia]/nus fị [l(io?)]... / Potitus est allesté en Narbonnaise et même à $\mathrm{Die}^{53}$, comme Valerianus $^{54}$.

Cette stèle à fronton triangulaire, aux lettres simplement correctes, aux moulures sans ressaut, avec la dédicace $D$ (is) $M$ (anibus), constitue le type de monument funéraire le plus répandu dans les trois derniers quarts du II et la première moitié du $\operatorname{III}^{\mathrm{e}} \mathrm{s.}^{55}$.

11. Épitaphe inédite et perdue, connue par un estampage du $\mathrm{D}^{\mathrm{r}}$ J.-D. Long ${ }^{56}$, avec l'indication manuscrite suivante : Rue de l'Évêché (à Die). Larg. : 0,28 m; h. : 0,57 m (dimensions approximatives).

\section{ATTIGIAN $\mathrm{L}$ \\ I BRIT'TIVS \\ IT.CVS F \\ ARI.E..A. \\ IMI.FILIAE: \\ PIENTISSIM}

Lettres peu profondes et peu régulières, semble-l-il, de $0,033 \mathrm{~m}$ de haut. Texte trìs difficile à lire.

L. $1: L$ peu sûr.

L. 2 : I initial peu sùr.

L. $3: F$ peu sûr.

L. $4: I, E$ et A peu sûrs.

L. $5: I M$ peu sùr.

L. $6: M$ mutilé.

Il ne peut être question de vouloir restituer avec exactitude ce texte, qui apparait cependant presque complet à gauche et à droite. C'est à titre d'hypothèse que nous présentons le schéma suivant :

[D(is) M(anibus)] / Alliciañi $L \ldots / \ldots i$ Brillius / [u]it[ri]cus f[il(io)? / c]ari $[$ s(simo)?] $e[t] \ldots a \ldots / \ldots$. . im . . filiae / pientissim $[a e]$ /.

53 CIL XII, 2042, 2210, 2450, 4247, 4483, 5001, 5154,$5211 ;$ ILGN, 234 (Die:.

54 C. n. 27

55 H. I)ESAYE, op. cil., p. 65.

56 Musée de Die, fonds Charles Béranger.

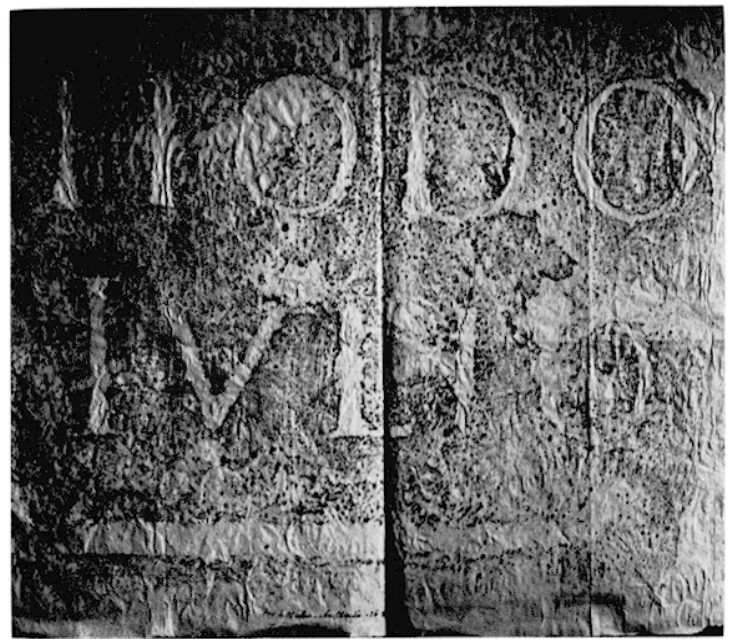

28 Epitaphe sur marbre, frottis du docteur J.-D. long ( $\left.\mathrm{n}^{\circ} 12\right)$.

Allicianus est connu dans la région ${ }^{57}$ et Britlius, d'origine celtique, a été signalé à Die même $^{58}$. Vilricus reste une hypothèse ${ }^{59}$ : ce serait par une extension de sens que l'auteur de l'épitaphe parlerait de fils et de fille.

12. Fragment d'inscription inédit et perdu, connu par un estampage du Dr J.-D. Long60, accompagné de l'indication manuscrite suivante : Sur le marbre. Alu moulin. 26 8bre 1849. Capit. Colson an $6 \% \mathrm{e}$ ligne. Larg. : $0,53 \mathrm{~m}$; h. : $0,45 \mathrm{~m}$ (dimensions approximatives). Moulure en bas ; paraît incomplet des autres còtés (fig. 28).

\section{HODO \\ IVLIO}

Lettres excellentes de $0,095 \mathrm{~m}$. I initial de Iulio dépassant la ligne.

Rhodo... / Iulio ... /

Rhodo- ne peut être que le début d'un cognomen d'origine grecque ${ }^{61}$, appartenant sans

57 CiL XII, I7Ix fCleon d'Andran:, 2533 et $5701,57$.

5x AE, 1969-1970, 348 = Ciallia, XXVI1, 1969, p. 207.

59 cif. CIL XII, 3628 . NIII, 2036.

60) Vusée de Die, même fonds.

61 (if. Rhodocus (:Il . XII, 1880, Rhodon (1713, Dieulefil ; 5699, 7 , Rhodope 1646, Die; 4.271, 4557 , $5 \times 56 ;$ XII, 2229, 2280;. 


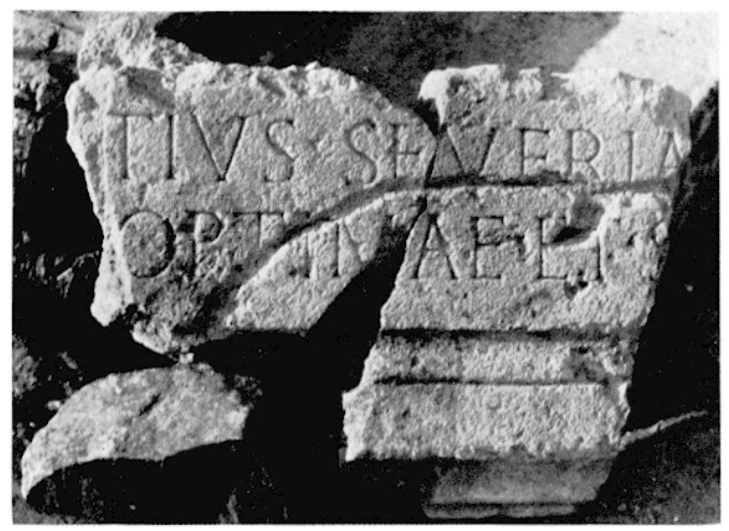

29 Rousset-les-Vignes. Fragment d'épitaphe no 13 .

doute à un affranchi ou une affranchie. Il peut s'agir du nom du dédicant, au nominatif, suivi du nom du défunt au datif, selon le schéma que nous avons vu au no 9.

I a beauté des lettres, très largres, le schéma possible de l'épitaphe, la matière même, qui fait penser à une plaque assez soignée, tout contribue à assigner ce fragment au I $^{\text {er }}$ s., peut-ètre même à sa première moitié.

L'intérêt du fragment serait accru si l'on pouvait préciser sa provenance. Il existe, en eflet, dans le Diois des dizaines de lieux-dits le Moulin : il $\mathrm{y}$ en a notamment dans les communes limilrophes de Die, a Romeyer. à Marignac, à Ponet, à Aix-en-Diois, ainsi qu'à I.uc. Le plus vraisemblable est de supposer que le Moulin est situé sur le territoire de la commune de Die. sinon le $D^{r}$ Long aurait sans doute précisé la localité. el de l'assimiler à un des moulins des quartiers de l'Aube. du Cagnard ou des Fabriques. Nous y avons vainement recherché le fragment.

Par le service historique de l'Armée, nous arons eu confirmation de ce que le $67 \mathrm{e}$ régiment d'infanterie a fait partie de l'armée des Alpes de 1848 à 1849 .

13. Fragments d'épitaphe en grès miocène, trouvés vers 1970 par M. Pierre Mourier, cultivateur, en ouvrant une fenètre dans sa ferme, au quarlier de suzou, a Rousset-lesVignes (canton de Grignan), sur la route de Valréas au Pègue. Larar. : $0.72 \mathrm{~m}: \mathrm{h}$. : $0,50 \mathrm{~m}$ : ép. : $0,1: 3 \mathrm{~m}$. Les deux fragments se raccordent. Texte complet en has (moulure sans ressaut). incomplet ailleurs ; on devine les traces d'une première ligne disparue. Au bas de la face écrite. moulure en doucine (fig. 29).

\section{TIVS -SEVERIA \\ OPTIMAE $\cdot \mathrm{ET} \cdot \mathrm{S}$}

Bonnes lettres de $0,065 \mathrm{~m}$.

Signalés par M. le Chanoine L. Van Damme, curé de Rémuzat; vus à la ferme en 1973.

...lius Se!u?!!̣a[nus / coniugi] oplimae et $s i b i: 1$.

Seucrianus est un cogromen bien attesté dans la région ${ }^{62}$.

Rousset-les-Vignes n'avait livré jusqu'à présent qu'une seule inscription ${ }^{63}$, mais le quartier de Suzou est tout proche du Pègue, qui s'est montré plus riche en vestiges épigraphiques ${ }^{64}$. C'est ici le cœur du pagus Aletanus ${ }^{65}$, qui relevait soit des Tricastins soit des Voconces vaisonnais ${ }^{66}$. Nous n'avons pas l'intention de traiter de ce problème. Ajoutons simplement qu'au Moyen Age Rousset, le Pègue, Montbrison et Taulignan dépendaient de l'évêché de Die, mais cela ne suffit pas pour attribuer le pagus aux Voconces de Luc et de Die, bien éloignés.

Nos fragments paraissent avoir appartenu à un texte connu par des copies de J.-NI. Suarès, évèque de Vaison au xvire s., et situé par lui à Valréas, dans la maison de M. de Rosset ${ }^{67}$ :

D(is) M(anibus) / Gelliae Paulinae / L(ucius) Cartius Seuerianus / coniugi oplimae et sibi / uiuus fecit $\%$

Hirschfeld a corrigé Cartius en Careius, mais nos fragments justifient la lecture de Suarès,

62 CII, XIl, 1267 (Orange, 1113, 1454 Vaison!, 1416 (le Barroux, 1597, 1643, 1649 (I)ie), 1728 (Rochegude), 1766 (Valence), 2667 (Cruasi.

63 Ibid., 1704 : épitaphe de Sévérinia Attica.

64 Ibid., 1705, 1706, 1707, 1708. 5853 est un texte médieval (Gallia, XXII, 1964, p. 265.

65 CII, XII, 1711 et 1708.

66 G. BARriol., Les peuples préromains du SudEsl de la Gaule, étude de géographie hislorique, Paris, 1969 , p. 266-267.

67 CIL XII, 1702: arca lapidea, Valriaci in aedibus $\Gamma$. de Rossel in implutio. 
au moins pour la dernière syllabe. Peut-ètre faut-il restituer Curtius ${ }^{68}$.

La vraie difficulté ne vient pas tellement de la localisation donnée par suarès -... il est facile de confondre le nom du village de Rousset avec le nom de la famille de Rosset que de la lecture de la fin de l'épitaphe. Nos fragments ne peuvent avoir comporté après et $s$ - beaucoup plus de trois lettres, si l'on en juge par ce qui a disparu à la fin de la ligne précédente. On en est réduit à restituer : et $s[i b i]$ / ou et $s[i b i$ u(iuus) f(ecit)] /, la moulure excluant la possibilité d'une autre ligne. On peut supposer que uinus fecil serait le développement tiré par Suarès lui-même des sigles $u f$ inscrits sur la pierre.

Si l'on considère la dernière ligne de nos

68 Curtius est un gentilice connu en Narbonnaise : ibid., 3773, 4755 . fragments, il nous manquerait à peu près la moitié de l'inscription, ce qui supposerait une pierre d'au moins $1,50 \mathrm{~m}$ de long. La moulure inférieure fait penser à un linteau plutôt qu'à un sarcophage. D'ordinaire, ces types d'épitaphes ne comportent que deux lignes et il faut vraisemblablement placer $D$ (is) M(anibus) aux extrémités de la pierre, ce qu'indique d'ailleurs suarès dans le manuscrit Barberini XXXVIII, 100.

Nous proposerions done la restitution suivante de CIL XII, 1702:

\section{GELLIAE PAVLINAE \\ D I.CVRTIVS-SEVERIANVS M CONIVGI OPTIMAE'ET·SIBI V F}

La moulure en doucine, la dédicace aux Iânes en abrégé, la beauté des lettres situeraient le texte entre 70 et 150 .

Henti Desaye. 